\title{
LAS ALLEGATIONES FISCALES (1642-1645) DE JUAN BAUTISTA LARREA
}

\section{Paola VOLPINI}

Università degli Studi di Napoli "Federico II"

El objetivo del presente artículo ${ }^{i}$ es mostrar algunas observaciones surgidas a raiz del análisis de las Allegationes Fiscales, una de las dos obras más importantes de Juan Bautista Larrea ${ }^{2}$, jurista español que ejerció de oidor en la Chancilleria de Granada y posteriormente de fiscal del Consejo de Hacienda ${ }^{3}$, durante el valimiento del Conde Duque de Olivares, reinando Felipe IV.

Es preciso detallar algunas características de la obra, antes de pasar a su análisis. Para esto es útil empezar por el texto, cuya lectura permitirá mostrar las necesidades a las cuales tenía que responder una allegatio. Voy a confrontar con tal fin dos citas sacadas de dos versiones diferentes de la misma alegación, para aclarar el recorrido jurídico y editorial de la allegatio. Ésta es la primera versión:

POR / EL REAL FISCO, / EL DOCTOR DON IVAN / Bautista de Larrea, cavallero del Orden de Santiago, Fiscal / del Consejo. / CON / EL DUQUE DE ARSCHOT, / Principe de Aremberg, Cavallero del Tuyson, / Gentilhombre de la Camara de su Magestad, de / los Consejos de Estado y Guerra de Flandes, Go- ? vernador de la Provincia de Namur, Caçador / y Montero mayor de los Estados y Provincias de Flandes. / SOBRE / LA CULPA QUE SE LE IMPUTA EN / el trato sedicioso que para levantamiento de las Provincias fieles / y obedientes de Falndes hizieron los Príncipes de Spinoy, / Barbaçon, Condes de Egmont, y de / Henin.

Se trata de la portada de una alegación que Larrea, fiscal del Consejo de Hacienda, redactó en favor del Fisco con vistas al proceso sobre el duque de Arschot ${ }^{4}$. Por lo que al tipo-alegación en idioma vulgar se refiere, hay que notar lo siguiente: se trata de una memoria de parte, redactada por el mismo abogado que 
luego la presentará en el proceso (siendo diferente de lo que ocurre, por ejemplo, conlos Consilia ${ }^{5}$ ); el abogado (en este caso el fiscal del Consejo de Hacienda) usará dicha memoria con objeto de enriquecer, fortalecer y completar su tesis.

En las alegaciones se abordan algunas cuestiones; se citan a auctoritates que apoyen la opinión a defender; se discuten las opiniones de la contraparte ${ }^{5}$. Se produce, pues, de forma evidente, cierta fusión entre la ciencia jurídica y la práctica forense. Con los dos aspectos -el más directamente ligado a la solución del proceso y el que tiene que ver con la ciencia jurídica-, se corresponden en cierta medida las dos versiones de la allegatio: la primera, en idioma vulgar, relacionada (directamente) con el pleito; la segunda, en latín, que es una traducción y parcial adaptación posterior ${ }^{7}$, en la que desaparecen en parte, por ejemplo, las referencias a personas $\mathrm{y}$ hechos

He aquí, por fin, el comienzo de la alegación arriba citada, después de haber sufrido dichas modificaciones en su traducción al latín:

In coniuratione seditionis, qui eius scientiam habuit, et non revelavit Principi, vel $a b$ eo interrogatus, illam negavit, qua poena puniendus ${ }^{8}$.

Hay que notar, acerca de la forma y de los cambios introducidos, que la modificación parcial se debe sobre todo al cambio de destinatario: el auditorio de las alegaciones sueltas en castellano estaba compuesto por colegas de Larrea que actuaban en un ámbito espacial y jurídico parecido -sino llegaba a ser igual-, al de Larrea, es decir, un auditorio de magistrados; en cambio, la recopilación en latín estaba destinada a un público compuesto en su mayor parte por juristas que ejercían su profesión en otras realidades, con rasgos similares debido a la coincidencia de las fuentes del derecho, pero que, además, pertenecían cada uno a un contexto social y político propio. De todas maneras, el carácter inicial estrechamente entrelazado con la práctica permanece también en la forma siguiente (en latín) de las alegaciones. Se ha tratado porque no hay que olvidar el origen -la forma anterior- de las alegaciones, aun en el caso, que se da aquí, de no volver a hablar de ello.

El texto que se ha estudiado está compuesto por más de un centenar de alegaciones que Larrea ha traducido al latín y, como ya se ha apuntado, adaptado parcialmente; dichas alegaciones constituyen el producto de su actividad de fiscal (quien instruye una causa) del Consejo de Hacienda, que duró aproximadamente de 1634 a $1638^{\circ}$. En ellas se trata tanto de la administración ordinaria del Consejo de Hacienda (legitimidad de los contratos, disputas sobre asientos), como de casos que no entraban en el ámbito específico de la profesión de Larrea (acusador de conspiradores), o de cuestiones de alta política (disputas con las Cortes, donativos). En conjunto la administración ordinaria prevalece presentándose más a menudo y de forma cíclica. 
El estudio de la obra de Larrea está por hacerse prácticamente en su totalidad. Antes de la Tesi di Laurea en la que se basa este artículo, el único trabajo utilizable era el de Salvador de Moxó ${ }^{10}$, quien se interesó sobre todo por la contribución de Larrea en la política de recuperación de Alcabalas de permisión o tolerancia: en este contexto Larrea había cumplido un importante papel, apoyando con esmero la causa regia. Esta aportación se refleja en las Allegationes Fiscales, en las que se encuentran algunas alegaciones dedicadas a dichas alcabalas ${ }^{11}$. S. de Moxó analizó detenidamente esta parte -importante aunque trata tan sólo un tipo de cuestiones-, y propuso una interpretación de la obra de Larrea de tipo regalista.

Otros autores han abordado la obra de Larrea de forma limitada ${ }^{12}$ o han acercado su obra a la de otros, para mostrar el punto de vista madrileño sobre temas analizados en otros ámbitos ${ }^{13}$. De todas formas, el único estudio de interés sigue siendo el de Moxó.

A través de algunas referencias a las diferentes fases de la elaboración de las Allegationes Fiscales se ha dibujado la figura profesional -de magistrado y juristadel autor: ahora se buscará información sobre su colocación política, analizando las dedicatorias -diferentes para la primera y la segunda parte de las Allegationes Fiscales-, y poniéndolas en relación con algunos importantes acontecimientos de política interior.

Hay que notar que la editio princeps salió en dos tomos en 1642 y 1645 , esto es, justamente antes y después de la caída del valido conde duque de Olivares, que había ejercido dicho oficio ${ }^{14}$ durante veinte años. Se comprende pues que el análisis de las dedicatorias de las dos partes es signifiçativa con respecto del momento y de la posición política en la que Larrea desea situarse.

La primera parte, de 1642, está dedicada a Antonio de Contreras, quien perteneció al pequeño grupo de hombres de confianza de Olivares ${ }^{15}$. La dedicatoria a Contreras concuerda con las opiniones políticas de sostén al valido tal y como se dibujan en sus páginas. La segunda parte de las Allegationes Fiscales salió en 1645, o sea, dos años después de la caída del Conde Duque. En ella Larrea ha introducido un cambio: dedica el volumen a García de Haro, conde de Castrillo. El Conde, durante un breve periodo, tuvo la esperanza de alcanzar la cumbre del poder, pero la prematura muerte de la reina, a quien debía fidelidad, le hizo perder toda probabilidad de ser el nuevo valido $^{16}$. Finalmente Luis de Haro, sobrino de García, fue el nuevo valido ${ }^{17}$. Pero hubo una época en la que García de Haro y Avellaneda, y Luis de Haro y Sotomayor 
llevaron el gobierno conjuntamente ${ }^{18}$. Cuando la situación estaba por decidir -con mucha probabilidad a finales del 1642- Larrea desea dejar clara su voluntad de situarse del lado del ganador o, menos enfáticamente, de mantener su posición política. Su interés principal está en la cercanía al grupo directivo: durante la mayor parte de su vida profesional al lado del valido, pero no de forma irrevocable. Cuando cambia el panorama político, Larrea ajusta la dedicatoria.

Se puede afïrmar pues que Larrea es coherente en su adhesión política: su objetivo final es apoyar al poder político en su sentido teórico, y con tal finalidad va adaptando las dedicatorias a las personas que una y otra vez personifican dicho poder. Pero hay que puntualizar una cuestión: el concepto de Larrea de "poder en su modalidad teórica" tiene que ser al mismo tiempo colocado en su justo contexto. Según el sentir de Larrea no existe contradicción en el hecho de intentar fortalecer el poder monárquico sirviéndose de los lazos profesionales y personales que le unen con el destinatario de la dedicatoria (García de Haro). Como se verá en detalle más adelante, Larrea en su dedicatoria del volumen II a Garcia de Haro pone en evidencia que ambos (él mismo y García) tienen orígenes vascos y que tienen en común la experiencia estudiantil en el Colegio Mayor, donde se conocieron ${ }^{19}$.

Como se verá, a veces Larrea adopta posturas que contienen un sentido de fidelidad al Estado, o al poder estatal, con connotación moderna tal, que hacen a Larrea más estatal que al rey -ya que pide más constancia en la ejecución de los proyectos regalistas ${ }^{20}$. Este hecho, empero, no supone la ausencia de aspectos con connotaciones diferentes, como el interés en subrayar los lazos personales, entendidos como una razón más para convencer al rey de la fidelidad del autor, y más en general para reafirmar su linea política. El cambio de dedicatoria sirve para comprender la colocación política de Larrea: no necesariamente a favor del Conde Duque, pero desde luego con él mientras siga teniendo el mando. De todas maneras está conforme, a grandes rasgos, con los objetivos de fortalecimiento de la monarquía, objetivos de los que tanto hablaba el equipo directivo por aquel entonces ${ }^{21}$.

Es mi intención en esta primera parte investigar los casos en los que Larrea explicita su idea respecto de algunas cuestiones fundamentales sobre las prerrogativas reales. Se han destacado algunas posturas generales, aún sabiendo que nunca se pueden separar del todo del contexto en el que el autor las ha formulado. Si se buscan los cimientos a partir de los cuales el autor construyó su sostén a la política real, será escaso el material que se logre encontrar: la tarea de Larrea le lleva siempre, repito, a preferir el aspecto práctico al teórico. Aủn así, y aunque a veces Larrea tiene acceso sólo a partes del poder directivo y puede mostrar un aspecto limitado de los hechos, hay partes en su obra que permiten reconstruir su opinión sobre el orden, las prioridades, los valores que hay que aceptar. 
Por lo que a la cumbre del poder se refiere, Larrea, en una alegación de cierta importancia, tiene la oportunidad de formular la definición de rey legitimo, y la contrapone a la de tirano. La alegación trata de la posibilidad de matar (realmente fue un desafío para un duelo que nunca se llevó a $\mathrm{cabo}^{22}$ ) a un rey que no sea legítimo:

Et addendi plures, quos refert D. Solorzanus, ut tyrannus occidi possit, [...] nam quod tradit, legitimum Regem etiam si tyrannice dominetur, non posse a subditis occidi, aliter procedit quando iuste Rex fuerit, sed iniuste gubernat, et propter iniustitiam non debent Reges a subditis occidi, vel cum Regnum quod tyrannide inceptum, longo tempore et populorum tolerantia et approbatione in veram Monarchiam convertitur $[\ldots]^{23}$.

Hay que añadir que tradicionalmente no se ponia en tela de juicio el que un rey gobernase con justicia: era más bien una forma de diferenciarle del tirano ${ }^{24}$. Pero Larrea en este caso tiene el objetivo de incluir muchas situaciones en las que el rey sea legítimo. Y por ello se salta las normales limitaciones teóricas sobre la forma de gobernar del monarca. La condición inicial de tiranía se puede borrar a través de la posterior aceptación del rey por parte del pueblo, aceptación ayudada por el factor tiempo. Lo mismo ocurre en este otro caso: a un rey legítimo que gobierna de forma tiránica no se le puede pretender matar ya que el simple hecho de tener el trono de forma legítima prohibe discutir sobre la manera en la que ejerce su poder.

Desde el momento en que se acojan estas afirmaciones de Larrea como connotativas e introductoras de su pensamiento, es preciso no olvidar que para él tales afirmaciones tenían cierta importancia, ya que hacían de soporte teórico imprescindible, pero nunca llegaban a ser el centro de su argumentación. La fase teórica, que es lo primero que yo buscaría en el estudio del pensamiento de un autor, en el caso de Larrea no tiene la función principal. Parece -y se verá más adelante, a la hora de leer otras partes de la obra- que el autor trabajase a partir de lo concreto. Me detengo en esta cuestión porque me parece especialmente interesante, ya que ofrece la posibilidad de estudiar el desarrollo de un sistema de pensamiento complejo pero que está arraigado en lo concreto. Con ello no quiero llegar a concluir que las afirmaciones de tipo teórico que se encuentran en las Allegationes Fiscales no tienen interés; pienso más bien que hay que usarlas como filtro cuando se analicen otras.

En las oscilaciones debidas a las soluciones de los casos reales Larrea introduce a veces afirmaciones que quieren limitar el poder del rey. Es en éstas donde no hay que olvidar el substrato que Larrea ha expuesto: el tirano que se ha asentado en un pais desde hace mucho tiempo, el rey legítimo que no gobierna de la mejor manera, han llegado a ser ahora figuras institucionales y por lo tanto requieren ser tuteladas. El elemento más importante de la cita es que Larrea está dispuesto a prescindir del contenido de las acciones del monarca para sostenerle de cualquier forma. Es cierto que, en el desarrollo de las distintas alegaciones, Larrea preferirá usar más bien 
argumentaciones relacionadas con la "necesidad pública, urgente"; no obstante, ha querido introducir también otras afirmaciones para los casos extremos.

En esta parte, las afirmaciones de interés son las que tratan de la importancia de los tributos y de la posibilidad para el rey de cambiar las cláusulas de un contrato. Su análisis -nunca separado del contexto en el que fueron realizadas- permitirá conocer otros aspectos de las prerrogativas que Larrea atribuye al rey.

Por lo que a los tributos se refiere, afirma Larrea:

Et ideo ex iure divino Principibus competit potestas imponendi tributa... ${ }^{25}$

La facultad del rey para imponer tributos no se ponía en tela de juicio. Pero llegar a afirmar que dicha facultad le corresponde al rey por derecho divino -que entre los derechos que se refieren a los diferentes ámbitos (divino, natural y civil) es el que más dificilmente se puede criticar- significa tener el objetivo de asignarle poderes ilimitados.

Larrea afirma que el poder de imposición de tributos, que tiene origen en el derecho divino, fue posteriormente asignado al rey según el derecho de gentes (natural) y el derecho civil. Según todos ellos, pues, el rey tiene facultad para imponer tributos:

[Tras citar algunos autores] [...] qui omnes a iure divino originem trahere testantur, quod secutus fuit ius gentium et ius civile: nam ex omnium gentium instituto ratio naturalis insinuavit Principem eligendum, et illum sine vectigalibus non posse imperare, ut praedicti notarunt ${ }^{26}$.

En este caso, para una cuestión de tanta importancia, Larrea ha llevado sus afirmaciones hasta un extremo. El rey tiene que tener a su alcance toda herramienta que pueda necesitar para imponer los tributos que le corresponden. El autor, aunque en un momento posterior vaya a introducir algunos elementos con el fin de limitar los poderes del rey, en esta parte ha establecido el núcleo de su pensamiento acerca del tema. El rey tiene el control sobre los tributos; otros sujetos puede que tengan derecho a opinar, pero sólo en ciertas ocasiones y cuando el rey considere que así debe $\operatorname{ser}^{27}$.

Larrea dedica una alegación introductoria a tratar la cuestión de los vínculos que las leyes introducen para el rey.

El debate había sido retomado por los autores de la Segunda Escolástica, quienes se habían detenido sobre las obligaciones del rey frente a las leyes, a partir de la distinción de Santo Tomás entre vis directiva de la ley, con "valor de regla, norma o dirección que toda ley implica" y vis coactiva "que obliga a cumplirla bajo pena"28 
En aquel ámbito hubo algunos autores, por ejemplo F. Suárez, quienes afïrmaron que el princeps legibus solutus está sujeto a las leyes respecto de su vis directiva ${ }^{29}$. La teoría escolástica, de hecho, dentro de sus diferenciaciones, habia asignado a la vis directiva una fuerza notable: si bien obliga al príncipe in foro conscientiae, "el peso de esta vi directiva no debe subestimarse dados los supuestos metapositivos con los que trabaja el sistema"130.

Sobre la materia hubo pues una contribución notable, que construyó un sistema de límites al poder real, en el cual la vis directiva tuvo un lugar importante. Larrea introduce algunas afirmaciones que tratan el tema. En primer lugar afirma que la vis coactiva no obliga al rey, de ninguna manera:

...illud etiam certum est, leges iuris positivi non obligare Principem vi coactiva, cum a nullo cogi possit, nec compelli qui superiorem non recognoscit ${ }^{31}$.

No era una labor difícil apoyar las afirmaciones sobre la vis coactiva. Más interés tiene la parte sobre la vis directiva. Larrea mantiene que existen ámbitos en los cuales no está permitido interferir con la acción del rey. Ya que el rey tiene la obligación de estar a la altura de la dignidad que su realeza le atribuye, no se le pueden imponer límites suntuarios:

[...] non solum vi coactiva, sed etiam nec directiva leges videntur ligare Principem, quando non conveniunt eius dignitati; ut cum pertinent ad rem sumptuariam in vestibus, et aliis rebus, de armis, formulis, et solemnitatibus, quae Principes non decent ${ }^{32}$.

A través de estas primeras afirmaciones, que quieren restringir las libertades del rey -ya que quién dice que existen ámbitos en los que no se le puede imponer nada al rey, supone que hay otros en los que sí es posible- parece que Larrea abogue por la tesis que obliga al rey, en base a la vis directiva, a respetar las leyes. De hecho cuando Larrea trata la posibilidad para el rey de no aplicar las leyes de manera uniforme, o sea, de no aplicarlas en igual medida para todos, afirma, apoyándose en una larga cita de Suárez, que el rey tiene la obligación de aplicarlas de manera uniforme tanto a si mismo como a los demás. Otra cosa es abrogar una ley y dictar otra. Pero mientras esté en vigor, el rey no puede quedar excluido del ámbito de aplicación:

[...] per abrogationem tollitur omnino lex, et ideo licet irrationabiliter fiat, valet, quia legem esse, vel non esse absolute pendet a voluntate legislatoris: at vero per dispensationem non tollitur lex, sed manente lege per talem dispensationem fieri tentatur, ut obligatio legis non uniformiter descendat ad eos, in quibus eadem causa, et ratio reperitur, quod est contra legem naturalem. [...] Et [Pater Suarez] [...] disputat an Princeps possit secum dispensare, et tradit ut licet respectu vassalli regulariter non sit nulla dispensatio, et quando subditus utendo dispensatione peccat 
venialiter, in Principe legislatore tradit esse peccatum mortale dispensando secum absque iusta causa, et teneri illam dispensationem revocare, et quoties voluntarie in ea permanet peccatum prosequitur ${ }^{33}$.

Desde una visión estrictamente teórica Larrea admite que las leyes vinculen también al rey. La distinción entre abrogación y derogación es fundamental en la alegación. En lo tocante a las palabras de Ulpiano princeps legibus solutus est, que en principio se referían a un ámbito restringido ${ }^{34}$, y habían sido deliberadamente interpretadas en un sentido amplio, hasta llegar a decir que el rey "era el supremo legislador, capacitado para promulgar y derogar leyes ${ }^{135}$, Larrea tiene una postura más limitativa. El rey se queda con el gran poder de anular una ley y sustituirla por otra más adecuada a la situación. Pero en la tarea de la administración del Estado con las leyes existentes, no puede variar el ámbito de su aplicación cada vez que quiera.

Tras el análisis de estas citas es preciso, sin embargo, añadir, a renglón seguido, que no ha sido posible encontrar ejemplos concretos en los que se haya aplicado dicha distinción entre abrogación y derogación. Así, aun pareciendo que el objetivo de Larrea es ponerse del lado de los que quieren poner límites a la acción del rey, realmente su finalidad es otra. Se verá, de hecho, a través del análisis de casos concretos, que Larrea no tiene intención de aplicar dichos límites al monarca.

Finalmente, Larrea se ocupa de otra cuestión que atañe al poder real. Es una cuestión que cíclicamente aparece en las Allegationes Fiscales: la obligatoriedad de los contratos estipulados entre el rey y los particulares ${ }^{36}$. Un tema que a menudo provocaba conflictos: por un lado el rey se comprometía como ciudadano particular a respetar los contratos, es decir, aceptaba colocarse en relación de igualdad con el otro contratante (por ejemplo, en cuanto a las fechas de caducidad de un contrato); por el otro, en cambio, si era preciso se acogía a su labor pública y en nombre del Estado se tomaba el derecho de no respetar los acuerdos estipulados. Es interesante notar aquí que el autor, tras analizar las facetas del caso, considera que en el pleito se están criticando las leyes del Reino. Y esto, desde luego, no puede ser:

[Tras citar a algunos autores] ex quibus apparet quanto iuris Regulis conveniant leges nostrae, et Iudices debeant earum tenorem observare, quia licet permissum sit de legibus disputare cum eas homines instituunt, tamen cum fuerint institutae et firmatae, non est permissum de illis iudicare $[\ldots]^{37}$

En este apartado Larrea no se dedica a investigar sobre el origen de las leyes: se conforma con admitir que han sido instituidas por los hombres, y al mismo tiempo quita fuerza a la afirmación. Los hombres, al entregar las leyes al monarca, confirmarlas y comprometerse a respetarlas, han concluido con la fase de aportación activa $^{38}$. A partir de entonces no tienen derecho a opinar; no pueden juzgar si las leyes son justas. Con lo cual el concepto de "contratualismo", considerado como intercambio continuo entre los diferentes sujetos sociales, es despojado de su 
principal significación; la "comunidad civil", tras entregar las leyes al rey, no tiene posibilidad de interacción con quien las administra.

Esta afirmación se parece a las que se han tratado anteriormente sobre el soberano legítimo: en aquella ocasión Larrea incluyó entre los soberanos legítimos a quienes con título legítimo- gobernasen de manera tiránica; en el caso presente sostiene que hay que respetar las leyes vigentes, sin posibilidad de juzgarlas. En ambos casos los súbditos tienen prohibido ejercer su sentido crítico sobre los acontecimientos. En todas las citas vistas, a través de modalidades diferentes, el autor llega a asignar al rey todo el poder sobre cada cuestión.

Es preciso entonces volver a la definición fundamental de soberano legitimo, para notar que cada vez que Larrea ha tenido la oportunidad de tratar las prerrogativas del rey, ha querido ampliarlas. Se puede decir que todas las veces que el autor se ha centrado en las posibilidades de actuación del rey en un ámbito concreto, ha terminado diciendo que el rey es de hecho legibus solutus ${ }^{39}$. Sin embargo, hay que añadir que no lo ha hecho preliminarmente. Esto no significa a mi parecer que Larrea quiera realmente limitar los poderes del rey. Parece más bien que intente estar en los dos lados a la vez: no comprometerse demasiado con el rey, cuando la cuestión es exclusivamente teórica, y alegar razones excepcionales cuando sea necesario. Todos los casos concretos según Larrea son necesarios, de acuerdo con la idea de gobierno que apunta a la ampliación del poder real.

\section{Parte segunda}

Después de haber trazado las bases del pensamiento de Larrea, y las herramientas que el jurista ha utilizado para apoyar al rey, es posible comprobar en situaciones concretas cuándo fue necesario usar dichas herramientas, cuáles fueron los objetivos elegidos como principales y los conflictos en los que Larrea tuvo que demostrar su lealtad y capacidad profesional.

Como ya se ha apuntado en la parte introductoria, se ha centrado el análisis en algunos temas-clave, a partir de los cuales se alcanzará una visión de conjunto tanto del pensamiento como de la actividad de Larrea. Dichos temas se refieren a las relaciones del rey con la nobleza y con los letrados: relaciones no sencillas, teniendo en cuenta la competencia entre nobles y togados en la asignación de oficios en el sistema administrativo del Estado, más cargadas de conflictos a raíz de la política de enajenaciones de oficios públicos que el Estado estaba llevando a cabo por aquel entonces. Relaciones que cobran todavía más interés, ya que Larrea se considera afectado por esta política real no sólo en cuanto fiscal del pleito a instruir, esto es, cumpliendo con su deber, sino también como perteneciente al grupo de los letrados. 
Además, va a ser objeto de análisis en este ensayo otro aspecto de la relación entre adhesión política y figura profesional de Larrea: se trata de la cuestión del apoyo del monarca a la labor de los magistrados en los conflictos con la nobleza en el contexto local.

Para las cuestiones que se van a tratar son útiles unas notas iniciales sobre la relación entre Larrea y el valido ${ }^{40}$. El Conde Duque emprendió varios caminos con objeto de lograr la participación de todos los reinos que formaban la monarquía hispánica en la financiación de los gastos de guerra. A lo largo de la década de 1620 había ideado, y en parte activado, la Unión de Armas, proyecto que suponía la distribución del cargo de los gastos de guerra entre los distintos reinos, según la capacidad contributiva de cada uno ${ }^{41}$. Más adelante, cuando quedó claro que no iban a llegar todas las adhesiones esperadas al proyecto de Unión de Armas, el Conde Duque buscó nuevas formas de financiación: no volvió a elaborar, como para la Unión de Armas, un proyecto de conjunto, en el que estuviesen implicadas todas las entidades que componían la monarquía, sino que prefirió tratar separadamente con los distintos grupos sociales, algunas veces apoyándose en relaciones cuasipersonales, otras veces apelando al cumplimiento de antiguos servicios debidos al rey. De todas formas, los primeros años del valimiento del Conde Duque trajeron cierta confianza, y de hecho el valido logró que muchos letrados participasen en su proyecto político. Larrea fue uno de ellos. Participó y se distinguió en la difícil labor de recuperación de las alcabalas detentadas por particulares ${ }^{42}$. En general se mantuvo del lado del valido. Pero el Conde Duque apuntaba primeramente hacia una política de fuerza: cuando tuvo claro que el proyecto de Unión de Armas, así como había sido elaborado, no era viable, Olivares buscó otros medios que le garantizasen la eficacia. A veces prefirió trabajar a través de Juntas, y en general no descuidó nunca su objetivo, o sea, encontrar dinero para financiar sus proyectos. Hubo, pues, una evolución en la que quienes actuaban a partir de los canales tradicionales (en primer lugar, los Consejos) no siempre pudieron mantener su posición, y se vieron afectados ya que la importancia de su función fue disminuyendo.

El equipo directivo, preocupado por continuas y apretadas necesidades, no pudo, a veces, estimar en lo debido la aportación de estos funcionarios, que participaron en los proyectos del valido, y con cuyos objetivos llegaron, en parte, a identificarse.

En un contexto de reivindicación de la justa importancia de la labor desarrollada dentro de la administración, pues, habrá que leer algunas de las afirmaciones de Larrea.

En concreto, existen algunas afirmaciones sobre el concepto de "necesidad urgente" que permiten mostrar la participación de Larrea en la política del Conde 
Duque. Dicho concepto, perteneciente al nivel superior de gestión del Estado en el que los súbditos no tienen derecho a opinar, se introdujo debido al clima de urgencia que impregnaba los escritos de la época ${ }^{43}$. La exposición de Larrea sobre esta cuestión es densa y llena de interés. Dejando a un lado los casos en los que es posible declarar la situación de "necesidad urgente", Larrea tiene el objetivo último de sustentar al Estado, por lo que considera que hay que proporcionar al rey la mejor herramienta para ello. Vuelve muchas veces sobre este concepto, adaptándolo a los distintos casos que trata. El sintagma, en el que "urgente" puede sustituirse a veces con "extrema", contiene el núcleo del poder del rey de imponer tributos:

...necessitas quae impellit ad petendum tributum sit adeo urgens ut nisi ei ocurreretur posset timeri periculum in publico Regni statu, quo caso necessitas extrema dici poterit, iuxta quod tradiderunt Divus Thomas, [...] Vasquez [...] qui tunc extremam necessitatem iudicarunt, quando cum ea aliquis sustineri non potest, unde quoties vectigalibus non concessis in periculum adducentur dignitas Regia et Regiminis solius status [...]. Et ideo Divus Thomas [...] tradit necessitatis proprium esse non subdi legibus, et facere licitum quod iniquum carere lege, et propter eam iura civilia transgredi pluribus probavit, D. Salgado [...] D. Castillo [...] D. Solorzanus ${ }^{44}$.

El fundamento de su discurso se encuentra en la afïrmación según la cual los preceptos de las leyes cesan en casos de urgente necesidad. Colocando esta definición en su contexto, es de suponer que entre los años 1620 y 1640 fácilmente se declarase estar en tal condición, y en consecuencia necesitar la imposición de nuevas contribuciones ${ }^{45}$. Es interesante detener un momento el análisis en el concepto de necesidad urgente, según el uso que de ello hizo el autor: quisiera subrayar que Larrea no usa el concepto de forma instrumental, apoyándose en ello cada vez que quiere legitimar un uso excesivo de los poderes por parte del rey. Para que la necesidad llegue a ser urgente es preciso examinar todas las razones por la cuales, por ejemplo, cierta intervención armada fuese inevitable. Si había alguna posibilidad de evitarla, y con ello la imposición de nuevos tributos, no existía la condición necesaria para apoyarse en la necesidad urgente. $Y$ es que Larrea conoce bien la situación constante de apuros de la Hacienda real, y por lo tanto considera arriesgado imponer nuevos tributos. Mantiene que la necesidad tiene que ser urgente o temer fuertemente que llegue a serlo, para imponer tributos que sino serían ilícitos ${ }^{46}$.

La adopción del concepto de necesidad urgente es indicativa del tipo de participación política de Larrea. Se trata de cumplir con uno de los aspectos más relevantes de su deber, en su vertiente tanto técnica como política: aplicar a los distintos casos concretos un concepto útil para la monarquía. 
Frente a la política de fortalecimiento de la monarquía, que, como se ha visto, Larrea apoya en general, va a ser interesante analizar los parámetros uilteriores que el autor aplica a veces. Se va a estudiar aquí un episodio acerca de la importante cuestión de la función de los letrados:

Excellentissimo, et Illustrissimo Principi, Dom. / D- GARCIAE DE HARO / AVELlANEDA, / Comiti de Castrillo, Equiti Ordinis de Ca- / latrava, et Commendatario de la Obre- / ria, a Consiliis Potentissimi Hispaniarum i Regis Catholici Philippi IV, in supremis / Senatibus Iustitiae, Camerae, belli et / status, Praesidis Consilii Indiarum, et / Regalis Patrimonii Prudentia et sapien- / tia insigni, negotiorum dexteritate felici, / iustitia, et omnibus virtutibus praeclaro, / S. F. / E. i D. C. / Haec quae de Iuribus Regalibus (EXCELLENTISSIME DOMINE) in hac secunda Allegationum parte in lucem edimus, te Patronum ambiunt, ut nec, si mittere alio vellem, possem, nec possem, vellem. Nullus maiori conatu et diligentia quae ad Regis nostri servitium spectant, disponere curat, nec magis viriliter exequitur, inde omnia, quae ad Regalia pertinent, te ad illorum tutamen debent compellere, praesertim me insinuante, et scribente, qui a te maximis beneficiis affectus, a tempore, quo in nostra iuventute in Collegio maiori Conchensi simul in iuris scientia plures annos impendimus, ubi talem Prudentiae et sapientiae indolem exhibuisti, ut semper omnes augurarentur, quae postea in Collegii nostri decus, Hispanie splendorem, et Regis nostri utilitatem et servitium operatus $[\ldots]^{47}$.

He seleccionado esta cita de la dedicatoria del segundo volumen de las Allegationes Fiscales, publicado en 1645. En ella Larrea se detiene en hechos como la coincidencia en el mismo Colegio Mayor, el de Cuenca, y el mismo lugar de nacimiento con el destinatario de la dedicatorias ${ }^{48}$, García de Haro, quien, justo en la época en la que Larrea le dedica dicho volumen, parecía poder llegar a sustituir al Conde Duque en el valimiento.

Para profundizar en el análisis hay que incluir estos factores, recordando que el mismo Larrea desea que tengan un puesto de relieve, ya que van a constituir lazos potenciales para un fortalecimiento de su posición dentro del sistema de administración de justicia. Se puede intentar trazar ahora una figura más completa del autor: Larrea es un empleado del Estado que mantiene su propia red de relaciones profesionales y personales y, por esto, a la hora de enfocar algunos objetivos, no ha querido aplicar un solo parámetro. Él es un colegial, pertenece al grupo restringido de quienes han sido admitidos para estudiar derecho en uno de los Colegios Mayores de Salamanca ${ }^{49}$. Es un servidor del Estado, que ha aceptado participar en algunos importantes aspectos del proyecto de Olivares. En el punto álgido de su carrera además de reconocer un parámetro principal, el de la fidelidad a la monarquía, añade 
otro importante parámetro político: la protección, la revalorización ${ }^{50}$ del grupo al que pertenece.

Teniendo en cuenta estas notas preliminares, no sorprende la lectura de partes de las Allegationes Fiscales que contienen posturas no del todo favorables a la acción de la monarquía. El interés de dichos fragmentos reside en la presencia de interlocutores que pertenecen al grupo de los magistrados.

A lo largo del estudio se comprobará lo que se ha apuntado: Larrea se identifica con el gremio de los magistrados y juristas. Desde la visión de Larrea, los dos factores (fidelidad al rey y protección de los magistrados) no son contradictorios, por lo menos en su desarrollo teórico. Al contrario, él llega a afirmar que si el monarca no protege adecuadamente la labor de los magistrados, no podrá tener un Estado seguro, y tras la ruina de los magistrados vendrá la del propio rey. La cuestión del espíritu del grupo reaparece en distintas ocasiones. Adelantando aquí algunas consideraciones, parece que la oposición de Larrea a la venta de nuevos oficios ${ }^{5 i}$ es característica de este "doble sentir": es cierto que el Estado que enajena muchos de sus oficios no aplica con coherencia la política de fortalecimiento; pero además la preocupación se refiere al riesgo de pérdida de relieve político del grupo de magistrados.

Hay otro ámbito en el que Larrea considera que su instancia de protección de los magistrados es indispensable para que el Estado funcione y progrese en el camino de fortalecimiento. Se refiere no tanto a la vertiente administrativa de la profesión de Larrea (a la que hay que adscribir la cuestión de la venta de oficios, que se verá dentro de poco) cuanto más bien a su vertiente jurídica. El autor sabe que tratar los problemas de los magistrados supone enfrentarse con el poder mismo. Tiene claro que la realidad de la soberanía se mide evaluando la capacidad de quien tiene el poder de imponer a los demás sus reglas de justicia. Es más, Larrea pone de relieve este aspecto, con objeto de subrayar tanto el valor del oficio que está ejerciendo, como el del grupo al que pertenece. Afirma que para que un reino esté bien gobernado, no debe faltar una buena administración de justicia:

Nam vere nihil magis authoritatem Principis auget, quam qui eius nomine regimen exercent, et iustitiam administrant apud subditos, sine aliquo dedecore existere ${ }^{53}$.

Cualquier que sea la tarea del magistrado, para administrar justicia necesita el reconocimiento del rey. La conexión entre el poder, en su modalidad teórica que no se puede discutir, y los hombres que concretamente tienen que administrar la justicia, es evidente según Larrea:

Ideo maxime oportet Principem curare de Magistratuum authoritate, ut nihil sit quod possit illam laedere, aut eos impediat muneris sui obligationibus satisfacere, nam cum Magistratus subditos dirigere et corrigere, adversus illos iudicare debeant, aemulationem et odium excitabunt, nisi maxime condecorentur [...]. Et omnes, qui 
optime regendi praecepta insinuarunt, illud maximum censent, et velut omnium originem Iudices et Gubernatores revereri et periculosum Regnis esse censent, non tribuere magnam authoritatem, et venerationem exhiberi Magistratibus, ut possint libere iustitiam administrare, et Principem suum consulere ${ }^{53}$.

En la exposición de esta parte me parece que Larrea se deja llevar por la retórica, hecho que en su obra no suele ocurrir. A lo largo del texto, a la hora de abordar el tema de la necesidad de protección de los magistrados por parte del príncipe, entra de pleno en la retórica del "buen príncipe":

Nam valde notandum quantis vigiliis, laboribus et aerumnis Princeps debeat pro salute subditorum invigilare, et remotis regionibus, ut in Rege Hispano, salubres leges et decreta edicere, ut etiam ad remotissimas Indorum Orientalium, et Occidentalium Provincias, eius gubernatio et potentia se extendere debeat, et si quid in ea defecerit, deficiat simul Principis obligatio et munus, illud enim spectat ut pro subditis invigiler, et Rex commoda sua pro illorum commodis omittat, sui oblitus, ut de subditis recordetur, nihil enim velut homo sibi facere potest, sed totum ut Rex Regno debet $^{54}$.

Parece que a Larrea le afecta mucho la cuestión. Adopta un estilo de redacción diferente del típico "jurídico-neutral" e intenta transmitir -a mi modo de ver con bastante éxito- la sensación de malestar y falta de seguridad que a menudo envuelve al magistrado en el cumplimiento de su deber.

Para un rey tan atareado como el español, con aquella amplitud de posesiones que con razón tanto orgullo despierta, la acción de la justicia es condición sine qua non de un Estado presente. El autor realmente considera que la aportación de los magistrados es imprescindible, y desea que el Estado haga su parte, o sea, garantice su sostén en los casos en los que los abusos de los señores locales lo hagan necesario.

El hecho de que aquí Larrea se dedique a exhortar al rey es una señal, en mi opinión, de un malestar que el autor no puede callarse: la solicitud de mayor protección real, de mayor confianza en los magistrados frente a las acusaciones que se les dirigen, es algo que está presente en todas las alegaciones sobre los magistrados. Larrea reserva una alegación entera a la demostración del riesgo que reyes y pontífices han corrido por hacer de árbitros en contiendas internacionales. Concluye que mucho mayor será el riesgo que corren los jueces, que son ciudadanos comunes:

Ut notandum Principibus, proponimus quantum oporteat suis Magistratibus et iudicibus favere, quia nec Pontifices, Reges, sive alii excellentes viri, exempti fuerunt $\mathrm{ab}$ aemulatione, iracundia contra iudicem [...] ut inde [de casos famosos que adujo como ejemplos] notetur quantum privatus quisque Iudex, vel Magistratus periculis subiacebit, si potentiores pro iustitia administratione condemnaverit ${ }^{55}$. 
Aquí Larrea ha colocado una reflexión: si es cierto que a los reyes les corresponde el deber de arbitrar grandes contiendas, deber que está repleto de peligros, mucho más peligroso tiene que ser dicho deber para los magistrados, ya que les corresponde arbitrar causas casi de la misma importancia, pero sin tener el respaldo del temor que el soberano provoca en la gente.

El importante texto de Castillo de Bovadilla, de finales del siglo anterior, ya había descrito las malas condiciones en las que tenían que trabajar los jueces:

[...] en estos pueblos de vandos, y donde hay vezinos poderosos. es necessario tratarlos muy bien de gorra, y condimiento, y castigarlos quando delinquen, sin perdonarles nada: y assi lo he hallado por experiencia porque donde se delinque con el esfuerço del poder, es necessario rigor en la pena... [y además] tambien deve hazer el Corregidor, que los poderosos restituyan los baldios y concegiles [...] y que en los repartimientos generales de alcavales y servicios, y otros dacios y tributos, aya igualdad y proporcion ${ }^{56}$.

Pero Larrea considera que para tratar el tema es necesario tener en cuenta otro interlocutor: la comunidad. Alega además una razón de tipo social: puesto que la tarea de los magistrados afecta al bienestar público, le corresponde a la propia comunidad la tutela al magistrado. En esta cita Larrea aborda de forma indirecta el problema de la intromisión de los poderosos en la administración de la justicia en el contexto local.

Et inde pertinere ad Concilium urbis in communi defendere iniurias irrogatas Magistratui [...]. Et merito, quia cum salus Magistratuum publica sit, eius tutela ad omnes in communi spectat ${ }^{57}$.

Larrea propone dos órdenes de razones según las cuales es preciso proteger a los magistrados: el primero, ya mencionado, es de tipo político: si a los magistrados se les proporcionan los medios adecuados, podrán cumplir con su tarea dentro del proyecto de limitación del poder de los nobles. El segundo órden de razones se refiere al prestigio: para convencer al monarca, Larrea no teme afirmar que existe una contraposición entre los Grandes y los letrados. No niega que el rey tiene que favorecer tanto a los nobles como a los letrados, pero añade que sería conveniente para el mismo rey dar privilegios a los segundos, ya que toda dignidad que el monarca conceda a estos se reflejará en él mismo, mientras que toda la que asignase a los titulados será usada sólo por ellos, sin que el monarca pueda sacar ninguna ventaja de ello:

Auctoritas enim, quam consequuntur Regni Magnates titulati, et domini vassallorum, et Regni ornamentum sunt, ut coeli stellae, sed splendor hic etsi a Principe derivetur, totus illustrat Magnates, et dominos, et in eorum utilitatem cedit, nec aliquid ad Principem inde rediit ${ }^{58}$. 
La preocupación -grande pero no exagerada- que Larrea pone de manifiesto en esta cita muestra una participación que a mi parecer no puede ser justificada sólo en razón de los intereses del grupo. Otras razones contribuyen a definir su pensamiento. La adhesión del autor a algunas líneas políticas del conde duque de Olivares se desenvuelve al mismo tiempo que los valores que podrían asociarse al personalismo, $o$, de todas formas, que querrían favorecer únicamente a su grupo profesional. Pero Larrea no considera que desear un aumento del favor real hacia los magistrados constituya una petición para que se privilegie a ciertos grupos. Se coloca deliberadamente, desde una posición profesional y personal, dentro de un proyecto político que se está realizando, y juzga sus instancias como justas, por el hecho de presentarlas dentro de dicho proyecto. Parece estar pidiendo que se lleven a la práctica dichos proyectos, y dado que no es un político de la cumbre del poder, no se apropia de las contradicciones contenidas en el programa de Olivares.

Él ha aceptado la petición del valido de apoyar la política en contra de ciertos grupos. Ésta es la razón por la que se ha opuesto al decreto sobre las Alcabalas de permisión o de tolerancia en mano de los Grandes, con el que Felipe IV se reservaba su decisión ${ }^{59}$. Es la razón, también, por la que pide que los magistrados, invitados primero a sostener la lucha en contra de algunas oligarquías locales, sean equipados de los medios necesarios, es decir, de la protección del rey. Éste es, finalmente, su límite. No toma parte de la política de más alto nivel, no pertenece al grupo selecro de colaboradores del valido. Con su cargo y su carrera, que fue prometedora. posiblemente hubiese podido llegar a formar parte de dicho grupo. Pero si considera que, frente a un Estado que no cumple con sus compromisos, la postura más correcta es avisar del riesgo y quejarse:

Attendant ergo Principes, nam bonum, aut pravum nomen iustitiae administrationi connectitur, si vindicaverint calumnias in Magistratus, secure regnare poterunt, alias postquam ministros prostraverint, in ipsum Principem subditi insultabunt ${ }^{60}$,

no acepta la situación, ni organiza su reflexión y su proyecto político a partir de las cosas tal como son, elige pues colocarse en el nivel secundario, en el que se encuentran quienes ejecutan sólo aspectos parciales del proyecto ${ }^{61}$.

Analizada desde este punto de visto la postura de Larrea, se explica también la brillante consecución de su carrera: los enemigos de Larrea apuntaron a su persona como fiscal imparcial, y él, de hecho, participando sólo en algunos aspectos del programa del Conde Duque, procedió de dicha forma. Complicado va a ser aclarar hasta que punto tal postura se debió, en un nivel más profundo, a elección política propia. Seria útil, con objeto de una más completa comprensión de su pensamiento, esclarecer donde terminaba su participación no precavida (con el objetivo de restablecer el pasado) en el proyecto de Olivares, que tampoco fue precavido, y donde empezaba, al contrario, un discurso de tutela personal, quizás también de 
previsión política acertada. Sin 1legar con esto a asignar a su figura un valor mayor del que tuvo.

Dentro del sistema administrativo, a nivel central a menudo los miembros de los Consejos se veían apartados por quienes pertenecían a las Juntas, con el consentimiento del Conde Duque. A nivel local los magistrados tenían que enfrentarse a los poderosos de los lugares, y no estaban, según lo que describe Larrea, bien amparados por la monarquía ni tenían los medios necesarios para llevar a cabo su tarea.

Para retomar el hilo de lo que se ha dicho hasta aquí, parece ser que, sobre la administración central, Larrea no está del todo de acuerdo con la forma de actuar de Olivares: si bien es cierto que el valido y el fiscal comparten algunos objetivos, el segundo considera que a veces los magistrados y los miembros de los Consejos están apartados injustamente. Aparece entonces un corte que tiene relación estrecha con el espíritu corporativo. El mismo que vuelve a aparecer en el nivel local de la administración, a la hora de tratar la cuestión de la tarea de los magistrados que se enfrentan a los señores locales. Pero a este respecto la principal preocupación de Larrea son los abusos de los poderosos locales.

Por lo que se ha visto hasta aquí, se puede decir que Larrea tiene dos grandes objetos de interés: la principal referencia política, el Conde Duque con sus proyectos de reforma, sus posturas regalistas, y el colectivo profesional de los letrados, que tiene su justa colocación dentro del Estado, pero que a veces ve como se le aparta. De esta combinación de intereses -que algunas veces van en un mismo sentido y se suman, y otras tienen blancos diferentes y se obstaculizan- es interesante ver ahora el desarrollo, a través de las Allegationes Fiscales, en relación con una cuestión que tuvo mucha importancia en la España de Felipe IV, la venta de bienes del Estado ${ }^{63}$. Además, esta cuestión me llevará a tratar sobre la venta de vasallos.

Las ventas de bienes del Estado implicaron a diferentes grupos sociales, y de hecho el mismo Larrea, a mi parecer, tomó parte en el debate no solamente como fiscal sino también porque temía estar afectado por algunas enajenaciones hechas por el Estado. En la compra de bienes del Estado, sobre todo oficios, pero también otras regalías $^{63}$, como pastos, participó la nobleza menor y los grupos acomodados, rentistas y ricos aún no siendo nobles ${ }^{64}$.

El análisis de este grupo de cuestiones permite enfocar la figura de Larrea en un contexto que no sea exclusivamente monárquico. No se puede llegar a decir que se trate de un enfoque social alternativo al institucional: esto, con las fuentes usadas, no 
puede hacerse. Lo que se ha intentado aqui es desplazar un poco la visión, y enriquecer los cimientos del discurso sobre la obra de Larrea.

Es útil resumir rápidamente la situación del derecho en Castilla: en la época de Larrea la ley prohibia, teóricamente, cualquier tipo de transmisión de oficios a través de la venta. Esta prohibición era el resultado de la superposición de dos leyes: la primera, que prohibía de forma general la compra de oficios; la segunda, que sólo prohibia la compra de oficios con jurisdicción, de oficios "de justicia"60. Tras cierto tiempo quedó claro que la prohibición que cobraba eficacia era la segunda. Para los otros oficios, de todas formas, nunca se llegó a promulgar una ley que permitiera su venta, y esta ausencia provocó la necesidad de acudir continuamente a falsas donaciones de oficios por parte de la monarquía, a cambio de dinero por parte de particulares. Cuando era un particular quien quería vender el oficio, afirmaba que deseaba "renunciar" a él en favor de alguien. En los casos en los que se vendían oficios importantes se respetaban las fórmulas oficiales, mientras que para oficios menores la venta se llevaba a cabo de forma más evidente ${ }^{66}$.

Tomás y Valiente ha propuesto una división según la cual, en la práctica, se podían vender tres tipos de oficios: "de pluma" (por ejemplo, escribano), "de poder", (por ejemplo, regidor o alguacil), y "de dinero", (por ejemplo, contador, receptor) ${ }^{67}$. Cuando los oficios se vendían perpetuamente, por juro de heredad, a la Corona le tocaba una cuota sólo por la primera venta, y no cada vez que ocurría un traspaso del oficio entre particulares. La práctica de las ventas empezó a cobrar importancia en la segunda mitad del siglo $\mathrm{XVI}^{68}$ y alcanzó la cumbre en la primera mitad del siglo siguiente. La monarquia, cuando necesitaba rápidamente dinero, acudía a menudo a las ventas, pero nunca de forma sistemática. En los casos en los que ya no habia oficios para vender, llegó a crear nuevos oficios que se solapaban con los que ya existían. Como podrá verse más adelante, éste fue uno de los rasgos principales del asunto $^{69}$. De todas formas, la costumbre dejaba claro, ya en la época de Larrea, que el objetivo de las renuncias era la venta ${ }^{70}$.

Las alegaciones que se van a analizar abordan dos cuestiones relativas a las ventas: el pensamiento de Larrea, a favor o en contra de las ventas, junto con las necesarias distinciones según el pleito tratado; la dificultad de aplicación de las prohibiciones.

Una alegación que se puede definir como típica sobre el tema es la que discute la licitud de la renuncia en Castilla de un oficio no renunciable ${ }^{71}$. Se trata del oficio de Alcalde de saca, que controlaba la importación de metales nobles. Larrea critica a quienes afirman el que dicho oficio sea renunciable:

Haec controversia multoties exorta fuit in Senatu regalis Patrimonii circa officia quae dicimus Alcaldes de sacas nam aliquando invenitur horum munerum renunciationem factam, et si postea per obitum obtinentis nova concessio a Principe 
fieret, quo casu qui renunciationem intendunt, allegant consuetudinem, ut ea officia renuntientur ex qua dicta $l .17$ [que es el objeto de ésta alegación] prohibitio renunciationis aboleri posse intendunt ex vi et effectu consuetudinis ${ }^{72}$.

Hay algunos que consideran que, puesto que la costumbre es que el oficio sea renunciable, hay que declararlo formalmente renunciable. Larrea no tiene argumentaciones suficientemente persuasivas para esta cuestión. Afirma que el príncipe ha permitido renunciar a un específico oficio de Alcalde de saca porque así lo ha querido; por este hecho, continúa, no es correcto deducir que dicha facultad se haya transferido al oficio en sentido general. Aquello sólo fue un acto "facultativo" del príncipe, por el cual no puede instaurarse una nueva costumbre.

Larrea está tratando un caso real en el que se ha vendido un oficio que estaba prohibido venderse. Se trata, pues, de aquella forma ligeramente oculta de venta de la que se ha hablado anteriormente. Todavía será más típico el caso cuando se lean otras partes. Para apoyar su tesis, Larrea usa, entre otros elementos, la ley de los Reyes Católicos de 1480, que contiene una lista de los oficios que no podían venderse; dicha lista incluye el oficio de Alcaldía de saca ${ }^{73}$. A continuación Larrea analiza las leyes sucesivas, para llegar a concluir que ninguna anula la vigencia de la de 1480. Recuerda además que la disputa sobre dicho oficio había surgido más veces, y anteriores fiscales del Consejo de Hacienda siempre habían apoyado tesis semejantes a las sostenidas por Larrea, actual fiscal del Consejo de Hacienda:

Idque melius procedit, quia semper in hoc casu a fisci patrono contra allegatum fuit, hoc munus non posse renuntiari ${ }^{74}$.

Él se mueve en el contexto de un debate de larga duración, en el que el Consejo de Hacienda desarrolla una tarea defensiva de principios que la monarquía no siempre es capaz de llevar adelante. Una corroboración se ésto reside en la ley en la que Larrea basa su defensa: se trata de la primera ley que prohibia la venta, que se refería a todos los oficios y que, como ya se apuntó, fue en la práctica anulada por la emanación de aquella que restringía la prohibición sólo a los oficios con jurisdicción ${ }^{75}$. Larrea sabe que sus afirmaciones no están bien respaldadas. Es probable que la fuerza de la práctica a la que trataba de oponerse dejase claro a Larrea que tenía pocas probabilidades de éxito. De hecho, entre las argumentaciones a favor del Fisco, añade el carácter jurisdiccional del oficio de Alcalde de saca:

Sed tamen cum haec officia ex sua natura non admittant renunciationem, quia continent iurisdictionem, merito ex nullo actu renunciatio in eis locum habebit ${ }^{76}$.

Pero sobre este aspecto, que es el único convincente, no puede insistir. Si el oficio en cuestión hubiese sido incluído (hecho que no ocurrió), en la lista de la ley de Carlos V, la cual prohibía justamente la venta de oficios con jurisdicción, está claro que Larrea hubiese usado dicha ley como fundamento de su alegación. 
Larrea se encuentra en una situación difícil. Su deber consistia en contrarrestar las ventas, a través de las cuales la monarquía perdia cualquier derecho sobre el oficio vendido. Cita lo que puede citar, para mantener su tesis, aunque no puede aducir la ley vigente, porque va en contra de su tesis.

He aquí un ejemplo de lo que a menudo tenía que ser el entorno en el que se movía el Consejo de Hacienda (y sus fiscales): tenia el deber de proporcionar el dinero para los grandes proyectos que a menudo animaban al Conde Duque, pero no siempre tenía acceso a los medios necesarios.

A traves del caso analizado, que ha permitido por un momento seguir al jurista en el enredo de las leyes, mostrando cuáles tenían vigencia, y cuáles se transmitían por simple formalidad, es posible añadir algo sobre las obligaciones de Larrea. A menudo tuvo que cubrir con una pátina de legalidad la forma de actuar de la monarquía. O quizás, más honestamente, decidió dar apoyo a una parte de los proyectos de la monarquía que por aquel entonces expresaba la intención de apoderarse de algunas regalías que estaban enajenadas o que se estaban enajenando. Quiso apoyar a aquella intención que restiltaba ser la primera en sacrificarse en los casos de necesidad, cuando estaba en juego la supervivencia de la monarquía entera.

Es interesante analizar otro caso de venta tratado por Larrea, en el cual el oficio vendido es el de Alguacil Mayor ${ }^{77}$. El Alguacil mayor tenía funciones de policía ${ }^{78}$. Era nombrado por el Corregidor, el más importante oficial de justicia real de un lugar. El caso es interesante porque muestra la dura lucha en contra de ciertas costumbres. Concretamente se trata de la compra del oficio de Alguacil Mayor con la facultad de nombrar a todos los Alguaciles subalternos. El comprador afirmaba que la compra, puesto que incluía el nombramiento de todos los Alguaciles menores, comprendía también un alguacil en particular, al que se le confiaba el cobro a los deudores de los bienes públicos del lugar, esto es, los propios:

Lictoris maioris officium generaliter venditum, an omnes lictores minores, sine distinctione comprehendat ${ }^{79}$.

La quaestio da más detalles:

Venditio officio lictoris maioris alicuius urbis, et concessione facta, ut omnes lictores minores, vulgo «Alguaciles», ab eo nominentur, cui officium venditum, an possit nominare lictores, qui executores dicuntur, et eligi solent a concilio urbis, ut bona publica, id est, «propios», civitatis a debitoribus exigant ${ }^{80}$.

Se trata de un equívoco de terminología, del que se aprovecha el comprador para acaparar la mayor cantidad de prerrogativas: quien tiene que cobrar las deudas a 
través de la adquisición de los bienes públicos, al que se suele llamar Alguacil como a los demás Alguaciles que tienen tareas de policía, en realidad se llama Ejecutor. El hecho de que normalmente se le llame Alguacil, sin diferenciarle de los Alguaciles normales, no implica que las tareas sean las mismas. De hecho el nombre correcto es otro. Sobre todo, la diferenciación se debe a una distinción básica entre estos Alguaciles: los Alguaciles comunes son nombrados por el Corregidor, el Ejecutor es nombrado por el Consejo de la ciudad, o sea, el Corregidor junto con los Regidores y los Alcaldes:

Nam si alicui concederetur, vel venditum sit officium lictoris maioris alicuius oppidi, quem Alguacil mayor dicimus, data facultate, ut possit nominare omnes lictores illius territorii, et cum essent aliqui, qui a concilio populi nominarentur ad exequenda decreta Concilii, qui etsi nomine lictorum vulgariter appellarentur, tamen specialiter executores dicebantur, eorum nominationem et electionem non comprehendi concessione, vel venditione, ex qua electio, vel nominatio alicui datur ${ }^{81}$.

La cuestión es importante, ya que es señal de una tendencia por parte de los compradores, los grupos acomodados de los lugares, a apoderarse de prerrogativas mayores de las que les tocarían en los acuerdos de venta, aprovechándose probablemente de la insuficiente presencia del Estado en dichos lugares. Hay que recordar además que el sistema de ventas afectó principalmente a los oficios locales, por lo que es fácil suponer que a menudo los compradores intentasen operaciones como la aquí descrita. Frente al intento de usurpación, Larrea cumple la tarea de tutelar los derechos de la comunidad en contra de quienes tienen las posibilidades económicas de comprar los oficios. Pero sobre todo su tarea es amparar a la Hacienda estatal, que tenía que sacar lo más posible de las ventas, y no podía permitir que en una venta se incluyera un oficio que no se habia tenido en cuenta cuando se había calculado el precio.

Los primeros casos vistos son muy útiles para notar qué armas usa y a qué conflictos se enfrenta el jurista: unas veces pocas herramientas jurídicas, otras, la necesidad de luchar en contra de ambigüedades deliberadamente creadas. En el primer caso Larrea afirma que la declaración de oficio renunciable no es legal, y expresa su oposición en este sentido. En el segundo caso espera que las ventas fructifiquen todo lo posible, y por eso no quiere permitir que el comprador se lleve más de lo que estaba pactado, o sea, que incluya un oficio más en la compra. No se trata entonces de oposición a la venta de oficios, en este segundo caso, sino más bien de un intento de precaver daños mayores.

Probablemente muchos de los hombres que tomaban las importantes decisiones políticas de entonces compartían, en sentido teórico, la oposición de Larrea al sistema de ventas, abogando por proyectos de más amplia envergadura. Pero la situación económica y política del momento no permitía llevar a cabo aquellos proyectos de reforma que habian animado los debates ${ }^{82}$. 
La alegación que se va a analizar a continuación trata del derecho real del monarca de variar las fuentes de las cuales sacar el dinero necesario para pagar algunas deudas contraídas con asentistas. Éstos habían adelantado dinero aceptando que la restitución se hiciese con el que se sacara de la creación y venta de nuevos oficios. Para entender cual era el clima de urgencia, que estaba próximo a la pérdida de control, es rica en indicaciones la descripción que el autor ha colocado a comienzos de la alegación:

In hoc anno 1637, cum fere totus Christianus orbis bellis tumultuaret [...], necessum fuit, ut ad sustinendos exercitus, quos, Princeps noster semper habet in Germania, Belgio, Italia, et ut posset repellere Gallorum invasiones, [...] ut iam expedire valeret classes, quae exercitibus debent deservire, [...] longe pluris quam antea stipendiis militum maior summa pecuniarum destinaretur, in quo cum fere totus Orbis pessum ruat super humeros Regis nostri Catholici, illeque Ecclesiam Romanam, et fỉdem semper defendat, maxime eget stipendia solvere ex ingenti et admiranda potentia Imperii Hispani ${ }^{83}$.

Las deudas contraídas con los asentistas iban a servir para pagar los sueldos de los soldados que la monarquía de España tenía dispuestos en múltiples frentes al mismo tiempo. A la hora de contraer deudas, la monarquía establecía, como es natural, de donde iba a obtener el dinero para pagarlas. Una fuente básica era, por supuesto, la llegada de la flota con los metales americanos. Pero no siempre llegaba: las incursiones holandesas a veces se apoderaban de todo el cargo y, de todas formas, las cantidades que en esta época llegaban no eran suficientes para extinguir las deudas contraídas. Cada año de hecho se creaban nuevas fuentes de dinero, unas permanentes, otras con carácter esporádico. En el segundo grupo se puede colocar la creación y venta de nuevos oficios y la venta de algunos de los que ya existían. El problema que ha suscitado esta alegación es entonces que según el acuerdo con los asentistas una parte de la deuda debía ser pagada con las ventas de nuevos oficios, pero no fue posible encontrar compradores ${ }^{84}$.

Larrea afirma que el rey tiene derecho a pagar a través de otras fuentes, sobre todo a través de un donativo que las Cortes concedieron, a raíz de tan grave momento:

Cum igitur ex venditionibus officiorum ea summa sex centum mille aureorum non redigeretur eius, cuius defecerat solutio in pecuniis donativi negotiatioribus consignata fuit, illi vero admittere consignationem recusabant, quasi Princeps ad sui contractus observantiam adstringedus sit, cum in eo publicam exuat personam, et privatam induat ${ }^{85}$.

En el cuadro completo, entonces, se muestra, además de un fiscal que intenta limitar el proceso de las ventas, una monarquía que no siempre es capaz de poner en práctica lo que ha decidido. 
Larrea ha dado algunas informaciones: ha confirmado, por un lado, cual es uno de los destinos del dinero producido por las ventas y de sus lazos con la situación de grave necesidad de la Hacienda; por el otro, ha dado una muestra de la limitada capacidad de la monarquía de poner en práctica sus proyectos. No quiero concluir que las ventas tuvieron un éxito menor del previsto, sino más bien apuntar al hecho de que dichas ventas probablemente produjeron menos dinero de lo que la monarquía había previsto. Parece que esto fue característico de un momento posterior, en el que los mejores oficios ya se habían vendido, y empezaba a estar claro que la compra de oficios supernumerarios no era siempre un buen negocio.

Hay otra alegación que permite precisar el pensamiento del autor sobre la venta de oficios. Se trata de un texto que difiere bastante de las demás alegaciones. El autor pone una cuestión inicial:

De iure regio ad creanda nova officia Decurionum, Tabellionum, et similium, et an procedat, si in iam creatis, aut venditis Rex se obligaverit ad nova officia non praestanda ${ }^{86}$.

Hay que notar de inmediato que Larrea discute aquí de iure regio, hecho no común: normalmente, él organiza la alegación a partir de los derechos que el rey tiene, y no poniéndolos en tela de juicio. La cuestión en concreto trata del problema de los oficios acrecentados, y de la posibilidad para el rey de añadir oficios para una profesión para la que el rey había asegurado que no lo iba a hacer. A lo largo del texto Larrea presenta las dos soluciones opuestas ${ }^{87}$, y concluye que, por razones de deontologia, puesto que el caso todavía se está juzgando, prefiere no poner de manifiesto su opinión. Sobre esta forma de proceder hay que decir que Larrea, en los pocos casos en los que el pleito del que trata está todavía por juzgar, se abstiene de expresar su opinión. Hay que suponer, pues, que el autor tenía mucho interés respecto a esta alegación, puesto que ésta es su manera de abstenerse de opinar:

Ex quibus lector, quid in casu quando obvenerit, poterit decidere, quia facile est ex praedictis resolutionem admittere, ego interim animum non exprimo; quia plures hodie de hoc controversiae sub iudice pendent, et in re dubia nolim vel iuri Regali praeiudicium inferre, aut partium [...]. Illud tamen monendum censeo, ut quamvis officia publica vendi possint a Principe [...], tamen numquam ego venditionem Principem consulerem, sed quanto possit excusandam, quia [...] turpe lucrum esse, cum talia officia venduntur, quia qui emerit officium, illius exercitium vendere debet, et si cum iustitia venditur, nihil boni in Republica esse potest, et cito eam perituram $^{88}$.

Larrea ha usado una figura retórica, la preterición, para exponer de forma clara e inequívoca su oposición a las ventas que se están llevando a cabo en la Corona de Castilla $^{89}$. Las alegaciones vistas anteriormente tenían el fin de evitar una ampliación excesiva de las prerrogativas de los compradores. Sobresalía, es cierto, la voluntad 
del autor de no conformarse sin dar su propia aportación a la política de las ventas. Pero su contribución se había limitado al aspecto técnico y jurídico. La lectura de esta última cita permite aclarar porque Larrea quiere dar una aportación no sólo en razón de su deber profesional: sobre esta cuestión Larrea considera que el aspecto profesional no es el único a tener en cuenta. Coloca esta alegación -seguramente singular- porque espera dar una aportación que vaya más allá de sus deberes profesionales. No escribe exclusivamente en calidad de jurista, sino que piensa de manera inmediatamente política ${ }^{90}$ y considera que la política que está llevando a cabo la monarquía es negativa.

La alegación tiene además otros aspectos de interés: las ventas en cuestión causarían daños de distintos tipos:

Et addenda quae de similibus venditionibus officiorum, ut licet fieri possint, non tamen expedit ea facere [se refiere al ejemplo de los Reyes Católicos], [...] et homines inde provocantur magis ad adquirendas pecunias quam ad studia litterarum et probitatis, et qui haec officia emunt, ut pretium recuperent, non administrant ea ut debent, sed multa iniuste extorquent ${ }^{91}$.

El ataque a las ventas contiene también oposición a la costumbre por la cual quien se aseguraba un oficio se aseguraba de hecho una renta. A menudo el propietario del oficio lo pasaba a otro para que lo ejerciese, y él se quedaba con la renta. Así se desarrollaba aquel estilo de vida, deseado por muchos en la época de Larrea, que permitía vivir de la renta y no tener que trabajar. El autor no omite enfocar sus criticas a la venta de oficios también desde esta postura.

Por otra parte es posible que Larrea a la hora de redactar esta parte no haya tenido en cuenta únicamente el bien del Estado. Es probable que su fuerte sensibilización en estos temas se deba también a otras razones, o sea, a la inclusión de si mismo en el grupo de funcionarios que temían verse afectados por el aumento de los oficios. El hecho es que Larrea denuncia la nueva costumbre, que a su vez es apoyada por la monarquía. Sobre las ventas Larrea tiene que "repartirse" entre dos opiniones y objetivos: cumplir por completo con los deberes de fiscal, combatiendo las ventas cuando no sean legales, pero conformándose con las decisiones de la monarquía de nuevas ventas legales; referirse además a intereses personales y de su gremio, con el fin de defender la realidad a la que pertenece, y negarse entonces a apoyar la política de la monarquía de llevar a cabo nuevas ventas.

De hecho la carrera de Larrea se situa en su última época dentro de dos Consejos, el de Hacienda y el de Castilla: en ellos desarrolla las tareas típicas de su profesión, pero no en exclusiva. Su intención es expresar las exigencias del grupo formado a partir de los Consejos. De entre los consejeros Larrea se puede colocar con quienes deseaban una renovación desde el interior de la estructura, por lo cual no valoraban positivamente las maniobras del Conde Duque que a veces, frente a las resistencias 
de otros consejeros a su política, procuró no necesitar la aprobación de ninguno de ellos, creando estructuras de gobierno alternativas. No obstante, durante los primeros años del valimiento de Olivares hubo algunos, como el mismo Larrea, que confiaron en sus proyectos de renovación. Existe una parte sobre las ventas de oficios (se trata del incumplimiento de un contrato por el cual el rey se había comprometido a no vender nuevas plazas para cierta clase de oficios) en la que Larrea, tras exponer las argumentaciones a favor y en contra de la venta de nuevos oficios, añade:

Postremo etiam, numquam ego consulerem Principem, ut a fide data vel contractu aliqualiter deflectat, quia cum nullum pretiosius Principis pignus, quam eius verbum, et fides, et non observando vilescit, ut nullus ex vassallis de Principe confidat [...]. Et pluribus Sacrae Scripturae locis, authoritatibus, et exemplis comprobat Magister Marquez in Gubernatore Christiano [...] Principem, etsi censeatur esse supra ius civile, non tamen censetur esse supra ius gentium, ex quo a fidei datae observantiam adstringitur $^{92}$.

Para comentar la cita es preciso recordar que en otra alegación el autor estableció unas posibilidades bastante amplias en las que el tirano se volvería rey legítimo ${ }^{93}$. En esta alegación, en cambio, afirma que el rey tiene que respetar los compromisos, y no tiene porque alejarse de ellos. Se trata del tema del respecto a los contratos, pero el interés de Larrea se centra en el contenido del contrato, y no en la necesidad formal de que se cumpla. Puesto que se trata de la creación y venta de nuevos oficios, Larrea no está de acuerdo con las decisiones monárquicas.

El texto citado difiere de forma significativa de lo que se había visto anteriormente sobre los límites que Larrea considera necesarios para la acción del rey. Creo que la razón de este alejamiento de las opiniones precedentes del autor se encuentra en su oposición a la manera en la que el rey o el valido están usando los poderes reales. Larrea no suele escribir alegaciones en contra de la acción del rey ${ }^{94}$; en los casos que tienen validez general considera sin embargo que puede expresar su opinión también a la luz de otros intereses. Frente a una decisión regia de no respetar unos contratos estipulados en un ámbito en el que el autor consideraria correcto que se respetasen, critica la actuación del monarca, y aconseja que el rey se atenga a los principios. Desea que el monarca respete sus compromisos, porque quiere evitar que se lleven a cabo nuevas creaciones y ventas de oficios. "Plura politica"1)5: Larrea ha puesto de manifiesto su pensamiento sobre un asunto de mucha importancia.

Da un paso más: sale de las tareas típicas del jurista, distingue entre acciones más o menos negativas para la monarquía; además de estar en contra de la venta de oficios, de hecho, propone formas alternativas de producir dinero. Y es que considera que no todas las ventas de "bienes" de la monarquías son dañinas de igual forma.

A trayés del examen de un caso de venta de "vasallos"196, propone que se sustituya dicha venta a la de oficios. La venta de vasallos fue una forma más de obtención de 
dinero. La forma de realizar la venta, en cambio, la hacía bastante diferente de la venta de oficios que la monarquía estaba llevando a cabo al mismo tiempo. Puede ser interesante recordar lo que afirmaba A. Domínguez Ortiz al respecto. A la hora de analizar cuales fueron las facultades concedidas al comprador de vasallos, afirma que la jurisdicción del mero y mixto imperio, incluída en la venta de vasallos, "era sólo una cláusula de estilo, un fósil jurídico sin ninguna efectividad"'\$7.

La venta solía dar lugar a la formación de una zona de poder señorial. El caso tratado por Larrea, ligeramente diferente, presenta un lugar que quiere comprarse a si mismo. De hecho, después de una primera temporada en la que los vasallos se vendían a quien más ofreciera, la monarquía quiso favorecer aquellos lugares que, puestos a la venta, intentasen librarse de los lazos señoriales y quisiesen "comprarse". En principio el lugar podia participar siempre en la subasta (que era la forma común de vender "vasallos"), pero había ocurrido a menudo que el lugar, tras haber ganado la subasta con la mejor oferta, no tuviese el dinero suficiente para pagar lo pactado ${ }^{98}$. Fue por eso por lo que la monarquía decidió ayudar a los lugares que quisiesen comprarse, disponiendo que fuese suficiente que ofrecieran el dos por ciento más del precio inicial para que ganaran la subasta. Este derecho de prelación se denominó Tanteo ${ }^{99}$.

Larrea espera que se sustituya la venta de oficios con la venta de "vasallos". Su postura parece semejante a la descripción hecha por Dominguez Ortiz:

...nam ratio qua retractus in eis casibus admissus, ea fuit, quia ex venditionibus officiorum plura damna evenire possent, quia Gubernatoribus populorum iurisdictio restringebatur, quae damna cum aeque vigeant, et multo maiora in venditionibus iurisdictionum $[\ldots]$ et favore publicae utilitatis sit extensio ${ }^{\mathrm{i} 0 u}$.

Es evidente que Larrea considera que para la monarquía la venta de vasallos es menos negativa que la venta de oficios. Si se vendiesen demasiado oficios, el Corregidor se encontraria rodeado de personas que ejercen el oficio no por nombramiento real, sino más bien por compra. $Y$ de esta forma tendria graves problemas a la hora de ejercer su poder en el lugar. Larrea, que redacta la alegación para que el lugar tenga el derecho a participar en la subasta ${ }^{101}$, tiene el objetivo superior de convencer a la monarquía para que prefiera la venta de "vasallos" a la de oficios.

La venta de vasallos precisaba la aprobación en las Cortes, y así se hizo en los primeros tiempos de su práctica. Más adelante disminuyeron las formas de control. Pero en la época de Larrea todavía tenía su valor el mantenimiento de ciertas fórmulas, y que las ventas se hiciesen según algunas reglas. Recuerda el autor que ya en el tiempo de la primera venta de "vasallos", los veinte mil vendidos en 1626. los vasallos tenían permiso para participar en la subasta: 
Et in venditione viginti mille Vassallorum, quos Regnum concessit aperte id exprimitur, et ad retractus effectum arbitria, ex quibus pecunias ad pretii solutionem colligere possint Vassallis conceduntur ${ }^{102}$.

Admitir en la compra los lugares puede ser interpretado pues como una forma más para ensanchar y orientar el mercado hacia aquellas ventas que Larrea prefería porque eran menos dañinas, además de una manera de subrayar la libertad del príncipe para elegir la forma y los destinos de las ventas. 


\section{NOTAS}

1.- Este trabajo se origina en mi Tesi di Laurea, que fue dirigida por la Profesora Elena Fasano Guarini, en colaboración con el Doctor Michele Olivari, y leida en la Università degii Studi di Pisa: se titula Le Allegationes Fiscales (1642-1645) di Juan Bautista Larrea nel contesto politico e sociale della Spagna nell'età di Filippo $\mathrm{IV}$.

2.- La editio princeps de las Allegationes Fiscales è del 1642-45 (volumen 1 y II respectivamente); sale luego en 1651-52, en 1665-66 y en 1699, por lo que se refiere al s. XVII; en el s. XVIIl sale seguramente una edición en 1732; todos los ejemplares están impresos en Lugduni. Las Decisiones Granatenses, la otra obra importante escrita por Larrea, salen por primera vez en 1636-39 (también en Ludguni, en dos volúmenes); entre el s. XVII y el XVIII salen diez ediciones, cf. A. Pérez Martín e J.-M. Scholz, Legislación y jurisprudencia en la España del Antiguo Régimen, Valencia, 1978, donde los autores notan, p. 288, que sólo dos obras de este tipo se editaron más veces. Parece, pero no he podido averiguario, que las Decisiones pudieron haber sido editadas ya en 1617, cf. voz Larrea, Juan Bautista, de J. M. Garcia Marin, en M. Artola (dir.), Enciclopedia de historia de España, vol. IV, Madrid, 1991, p. 472, voz que, de todas formas, no contiene informaciones completas ni del todo correctas sobre el jurista. Para esta nota bibliografica he usado además la Enciclopedia universal ilustrada europeo-americana. Madrid, tomo XXIX, p. 882 (de este texto no he encontrado ni el director ni la fecha de edición); Gottlieb Föcher, C.. Allgemeines Selehrten Lexicon, Hildesheim, 1961; Nicolás Antonio, Bibliotheca hispana nova, Madrid, 1783, t. I; A. Palau y Dulcet, Manual de librero hispanoamericano. Segunda edición, corregida y aumentada por el Autor, Barcelona, 1954, t. VII, pp. 391-392. He encontrado todas las voces siguientes en K. G. Saur, Índice Biográfico de España. Portugal e Iberoamérica, Mónaco, New York, Londres, Paris, 1990: J. A. Álvarez de Baena, Hijos de Madrid, Ilustres Santidad, Dignidades, Armas, Ciencias y Artes, 1790, t. III; L. Ballesteros Robles, Diccionario Biográfico Matritense, 1912; Ramírez de Arellano, C. Gutiérrez de Salamanca, Ensayo de un Catálogo Biográfico de los Escritores..., 1894; J. de Rezabal y Ugarte, Biblioteca de los Escritores que han sido individuos de los seis Colegios Mayores.... 1805; A. Vidal y Diaz, Memoria Histórica de la Universidad de Salamanca, 1869 (la citas bibliográficas incompletas -el título incompleto, la falta del lugar o de fecha de edición- se debe a la forma de microficha de dicho texto, en el que no siempre está completa la referencia a la fuente. No me ha parecido necesario localizar todas las referencias correctas por el hecho de que se pueden encontrar reunidas en la citada recopilación). Finalmente, he completado las fuentes citadas con una comprobación personal en algunas bibliotecas, (la Biblioteca Universitaria de Pisa y la Nacional de Madrid), ya que ninguno de los textos citados contiene información del todo correcta. De no indicar lo contrario, las citas de las Allegationes Fiscales pertenecen a la edición del 1665-66, ejemplar de la Biblioteca Universitaria de Pisa comparado posteriormente con otro de la misma edición en la Biblioteca Nacional de Madrid.

3.- Hablo de las profesiones que cobran importancia en el estudio de las obras principales de Larrea. El autor tuvo varios oficios, último de los cuales fue el de consejero del Consejo de Castilla, cf. J. Fayard, Los miembros del Consejo de Castilla (1621-1746), Madrid, 1982, p. 509. El haber tenido dicho oficio durante una breve temporada, y al final de su carrera, provoca la ausencia de referencias a ello en las Allegationes Fiscales, por lo que no constituirá tema de interés en este ensayo.

4.- Ejemplar consultado en la Biblioteca Nacional de Madrid, cuya signatura está bajo el nombre del autor. Para la grafía del nombre "Arschot" he adoptado la que usa Larrea en la portada. Sobre la "Conjura de los nobles" se pueden ver los recientes artículos de P. Janssens, $L$ 'échec des tentatives de soulévemente aux Pais-Bas sous Philippe IV (1621-1665), en Revue d'historie diplomatique, 92 (1978), pp. 110-129, y La fronde de l'aristocratie belge en 1632, en W. Thomas (dir.), Rebelión y resistencia en el Mundo Hispánico del Siglo XFII, Acras del Coloquio Internacional, Lovanio, 1992, pp. 23-40.

5.- La principal diferencia entre allegationes y consilia (pro parie, pro veritate) reside en el hecho de que estos los encargaba el abogado de parte a otro jurista (a ser posible de renombre), mientras que la alegación la redactaba el mismo abogado que luego la presentaria en el pleito. Sobre la literatura juridica 
en época moderna, cf. M. Ascheri, Tribunali, giuristi e istituzioni dal medioevo all età moderna, Bologna, 1989 y A. Pérez Martín, J.-M. Scholz, Legislación y jurisprudencia..., cit.

6.- En epoca moderna la allegatio era un "generico atto di parte consistente nell'allegare fatti e ragioni a motivazione delle conclusioni proposte". La alegación "nel senso più pieno della parola [...] [se escribia] a illustrazione delle prove in precedenza addotte, a dimostrazione dei motivi di diritto su cui si reggono le istanze dei rispettivi clienti, a confutazione delle prove e degli argomenti portati dall'avversario"; ocurrió que İuego, en la práctica, con el nombre de allegationes se escribiesen textos de diferentes contenidos. Cito de la voz "Allegazioni" de P. Fiore en F. Calasso (dir.), Enciclopedia giuridica, Varese, 1958 , t. II, pp. $69-70$ y 70 respectivamente.

7.- Modificada sobre todo a través de la eliminación de algunos detalles referentes al hecho especifico. Hay que añadir que en el texto se encuentra, además, un grupo de alegaciones que al parecer no han sufrido modificaciones. Aparece, por ejemplo en la alegación LXXX -debida a una polémica sobre la fecha en la que debía empezar a correr un contrato-, la indicación del mes pero no la del año: información suficiente para quienes usasen el texto sólo en ei proceso, pero que pierde sentido para quienes quisiesen profundizar la cuestión en otro momento o en otro contexto.

8.- Se trata de la quaestio de la all. LXV, p. 329.

9.- A.H.N. Estado, leg. $6.399^{\prime}, 116$ y 118.

10.- Salvador de Moxó, La alcabala. Sobre sus origenes, concepto y naturaleza, Madrid, 1963.

11.- Precisamente las alegaciones de la V a la XVI (sobre un total de 120). Larrea dio una aportación importante: en ei s. XVIII los juristas del rey que trabajan para la recuperación de alcabalas detenidas por muchos nobles poderosos usaron a menudo las Allegationes, como apunta S. de Moxó, La alcabala..., cit.

12.- Cf. A. Domínguez Ortiz, La conspiración del duque de Medina Sidonia y del marqués de Ayamonte, en Crisis y decadencia de la España de los Austrias, Barcelona, 1973', pp. 113-153, que cuenta que Larrea participó en la detención del duque de Medina Sidonia.

13.- Me refiero a la opinión de P. L. Rovito, Respublica dei togati. Giuristi e società nella Napoli del Seicento, Napoli, 1981, quien cita las Allegationes Fiscales de Larrea cuando trata del tema de las visitas. Como he notado en la Tesi di Laurea, p. 220, considero que en este caso la extrapolación de la alegación del contexto haya provocado algunos problemas para la correcta comprensión dei texro.

14.- Sobre las caracteristicas del valimiento, que en el texto he denominado "oficio", que se adapta y modifica a lo largo de los diferentes reinados, y hasta en un mismo reinado (éste es el caso de Felipe IV, durante cuyo reinadio, excepcionalmente largo, hubo diferentes personas que tuvieron el valimiento y consecuentemente hubo distintas maneras de ejercerlo), cf. F. Tomás y Valiente, Los validos en la monarquía española del siglo XVII, Máadrid, 1963, 19832. Sobre las distintas evaluaciones deì roí de los hombres que ocuparon el puesto más cerca del monarca, $v$. infra, discusión aludida en $n$. 17.

15.- Sobre la dedicatoria colocada en la primera parte de las Allegationes Fiscales tengo que dar cuenta preliminarmente de una información equivocada que puse en la Tesi. En dicha ocasión afirmé que Larrea había dedicado la primera parte de las Allegationes Fiscales a Antonio Carnero, en lugar de a Antonio de Contreras. Ha sido probablemente un error de transcripción, Ilevado hasta la redacción final. Sólo posteriormente, más descansada y otra vez delante del texto, he visto el error. Sobre Antonio de Contreras. cf. J. H. Elliott, El Conde-Duque de Olivares. El político en una época de decadencia, Barcelona, $1991^{6}$, passim, que le incluye en el grupo restringido de consejeros y secretarios fieles del valido, cf. por ej. p. 545: "... el conde-duque tenía su propio círculo de consejeros íntimos, como el protonotario, José González, Antonio de Contreras y Hernando de Salazar...". 
17.- Cf. R. A. Stradling, Felipe IV y el gobierno de España. 1621-1665, Madrid, 1989, pp. 351-352, que niega que las tareas de Luis de Haro sean las que le corresponden a un valido; cf. además nota 77 de pp. 379-380, donde el autor da algunas referencias bibliográficas de los autores que, al contrario, consideran que Luis de Haro fue el nuevo valido. Sobre el valimiento es preciso recordar el fundamental estudio de F. Tomás y Valiente, Los validos en la monarquia del siglo XVII, Madrid 1990, (se trata de la edición revisada: la primera edición salió en 1963).

18.- Ésto, nota J. H. Elliott, se parece a los primeros momentos del valimiento de Olivares: "[el conde de Castrillo] aunque albergaba sus propias ambiciones, probablemente para entonces [finales de 1642] actuaba en connivencia con su sobrino, don Luis de Haro [...]. El afecto que el rey sentía desde su juventud por don Luis [...] convertía la activa colaboración del tío y sobrino -como ocurriera en la generación anterior con đon Baltasar de Zuñiga y Olivares- en un curioso expediente de cara a mantener el legado político del conde-duque en manos de su familia", El Conde Dnque..., cit., p. 621 ; también R. A. Stradling, Felipe $I$..., cit., se detiene sobre este aspecto, con un enfoque algo diferente: García de Haro llamaba a Luis de Haro "«mi sobrino y señor $» "$, p. 355.

19.- V. infra, n. 47.

20.- Me refiero a un caso que trata de un decreto regio por el cual el monarca se reservaba la facultad de decidir acerca de las Alcabalas de permisión detenidas por particulares, con to cual no abria paso a la instrucción de los pleitos para que dichas alcabalas volviesen a ser del rey. En la alegación VIII Larrea afirma que el decreto no impide que los fiscales sigan en su lucha en contra de ia detención de las alcabalas por particulares. La importante aportación de Larrea sobre las alcabalas no se verá en este ensayo, puesto que es la única parte de la obra de Larrea que ha sido estudiada ya, por S. de Moxó. v. supra, obra citada en n. 10.

2i.- La notable capacidad del autor de conformarse con los nuevos acontecimientos (el cambio del antiguo al nuevo valido) es realmente indicativa de la figura de Larrea. Desdichadamente no lo es de la misma manera para el análisis de las Allegationes Fiscales, puesto que se refieren probablemente todas a la epoca de valimiento del Conde Duque. Sobre la opinión que los contemporáneos tuvieron de Larrea, es instructivo lo que cuenta Benigno: cuando cayó el valido, a comienzos del 1643 , se publicaron unas acusaciones en su contra, en forma de panfleto anónimo (cuyo autor, por otra parte, se conoce: el oidor Andrés de Mena). El panfleto pedia que se instruyera una visita para investigar las responsabilidades del ex-valido acerca de la mala gestión del Estado. A la hora de indicar los nombres de los posibles jueces, y de las demás personas necesarias para la instrucción, el "anónimo" Andrés de Mena, portavoz de cierta nobleza contraria al Conde Duque, proponía la elección entre dos fiscales que, a la luz de la independencia mostrada en el ejercicio de la profesión, podian considerarse idóneos para la instrucción de la visita. Uno de ellos es Larrea: "...con un fiscal como el doctor Juan Baptista de Larrea, del Consejo...". Está claro pues que Larrea, por lo menos en la etapa final del valimiento de Olivares, supo quedarse por encima de las disputas de tal forma que luego los adversarios del valido le considerasen un fiscal imparcial. Cf. F. Benigno, L'ombra del rey. Lotta politica nella Spagna dei Validos (1598-1643), Catania, 1990. El texto del panfleto ha sido publicado por J. H. Elliott y J. F. de la Peña (dir.), Memoriales y cartas del Conde Duque de Olirares, 2 voll., Madrid, 1979-80, II, pp. 225-244 (que he podido consultar sólo parcialmente). La cita procede de p. 154, n. 51 .

22.- Se trata de la conjura del duque de Medina Sidonia y del marqués de Ayamonte. He aquí los momentos salientes del asunto: en agosto de 1641 se descubrió que el duque de Medina Sidonia, de la rama mayor de la fanilia del conde duque de Olivares, habia tomado parte en la organización de una conjura, cuyo jefe era probablemente el marqués de Ayamonte, con el fin de independizar a Andalucia. Cuando el Conde Duque se enteró, su principal preocupación consistió en evitar que se comprometiera el nombre de la familia. Ofrecer a sus enemigos la posibilidad de acusar a un miembro de su familia de 
conjura significaría entregarles una buena arma para un ataque público. Las informaciones sobre la conjura llegaron al Conde Duque antes de que ésta se llevase a cabo. El actuó de tal forma que la culpabilidad recayera sobre el otro noble implicado, que al parecer fue efectivamente el principal responsable, el marqués de Ayamonte.

Realmente no era posible probar nada en contra del duque de Medina Sidonia. No obstante, rumores sobre la posibilidad de su adhesión y acuerdo con el duque de Braganza, quien acababa de declararse rey de Portugal desconociendo la soberania de España, requerian una confirmación, mejor con carácter público, de la lealtad del duque de Medina Sidonia al rey de España. Hay que interpretar en este sentido el desafío en duelo que el duque de Medina Sidonia, en nombre del rey de España, hizo al duque de Braganza. Para una descripción detallada del asunto, cf. A. Domínguez Ortiz, La conspiración..., cit.; cf. además J. H. Elliott, El Conde-Duque..., cit., pp. 597-602.

23.- All. CXVI, 9, p. 192. El punto siguiente afirma que en caso de que el Reino haya sido usurpado tiránicamente, cualquier persona puede matar al tirano. Para la referencia al texto de las Allegationes el primer número, romano como en el texto, indica la alegación; el segundo, el punto preciso, respetando la numeración del índice de cada alegación. No indico en que parte de la recopilación (I o II) se encuentra cada alegación, porque en la segunda parte continúa la numeración de la primera. Incluyo el número de la página, referido a la edición que usé, del $1665-66$ (v. supra, n. 1). Mientras que la numeración de las alegaciones es progresiva, es importante saber que la numeración de las páginas va de 1 a 356 , alegaciones de I a LXVI, y vuelve a empezar de 1 hasta 228, alegaciones de LXVII a CXX y última. Para localizar las citas a través deî número de página, entonces, es necesario conocer también el número cie alegación.

24.- Cf. F. Tomás y Valiente, La Monarquía española del siglo XVII: el absolutismo combatido, en J. M. Jovier Zamora (dir.), Mistoria de España, vol. XXV, Madrid, 1982, pp. 21-82 (parte de un ensayo más amplio: El gobierno de la Monarquía y la administración de los Reinos en la España del siglo XVII, pp. 1-214, del citado vol. XXV de la Historia de España) afirma, p. 39: "para que cl Principe, cl rey absoluto, no pueda ser calificado de tirano es preciso, y suficiente, que cumpla las leyes del Derecho natural y de gentes y la ley divina. Es ésta una exigencia unánime. [...] Desde los glosadores hasta Bodino y hasta todos los escritores españoles del siglo XVII, el tópico se repite [...]. [El rey] si no cumple con la razón y la justicia, no es un rey justo, sino un tirano".

25.- All. LIX, 4, p. 299.

26.- Ibidem, 5 , p. 299

27.- Larrea dedica algunas alegaciones a asuntos en los que están implicadas las Corres. En eillas su posición no es rigida, y presenta diferentes connotaciones según la presencia de otros interlocutores. El tema es interesante y rico de sugerencias interpretativas, pero la falta de espacio impide verlo aquí. Además, su análisis implicaría la introducción de cuestiones que se saldrian de la coherencia del discurso. Para un examen detenido del tema, visto a través del pensamiento de Larrea, tengo que remitir a la Tesi, cap. IV, pp. 319-331.

28.- Cf. s. Tommaso d'Aquino, Summa Theologiae, Milano, 1988², I, II, qu. XVIC, art. 5, afirma, resolviendo las cuestiones puestas anteriormente: "Ad tertium dicendum quod princeps dicitur esse solutus a lege, quantum ad vin coactivam legis: nullus enim proprie cogitur a seipso; lex autem non habet vim coactivam nisi ex principis potestate. Sic igitur princeps dicitur esse solurus a lege, quia nullus in ipsum potest iudicium condemnationis ferre, si contra legem agat. [...] Sed quantum ad vim directivam legis. princeps subditur legi propria voluntate". Cf. además F. Tomás y Valiente, La monarquia española..., cit., pp. 21-82, de donde se han sacado las citas insertadas en el texto, pp. 33-34.

29.- Cf., además del texto de F. Tomás y Valiente citado en la nota anterior, P. Fernández Albaladejo, Los Austrias Mayores, en Domínguez Ortiz, A. (dir.), Historia de España, vol. V, Barcelona, 1988, pp. 10-171, sobre todo p. 76 y ss., donde se trata rápidamente a los principales autores de la Segunda 
30.- Cf. P. Fernảndez Albaladejo, Los Austrias Mayores..., cit., p. 76, que esboza sintéticamente la opinión de dos importantes autores de la Segunda Escolástica: según F. Suárez "la sola fuerza directiva de la ley puede llegar a producir «obligación grave», según la materia y el fin de la ley"; Vázquez de Menchaca "llegara a proponer la sumisión del príncipe «a las leyes civiles de su república» no sólo «en cuanto a las palabras», sino también en cuanto "al efecto y substancia de la obligación legal»".

31.- All. IV, 9, p. 16.

32.- Ibidem, 10, p. 16

33.- Ibídem, 26 e 27, p. 19, la primera parte es a su vez una cita de Suárez, lib. 6 de legibus, cap. 19, $n$. 7.

34.- Cf. G. Rebuffa, Jean Bodin e il «Princeps legibus solutus», en G. Tarello (dir.), Materiali per una storia della cultura giuridica, vol. II, Bologna, 1972, pp. 89-123.

35.- Cf. F. Tomás y Valiente, La Monarquia española... cit., p. 32.

36.- La cuestión de los contratos, uno de los grandes temas presentes en las páginas de Larrea, no se va a tratar en este artículo. Se hace referencia a ella en esta primera parte para mostrar la amplitud de las prerrogativas que Larrea atribuye al monarca. Una exposición detallada implicaría una ampliación excesiva de la perspectiva. En la Tesi, de hecho, ocupa un capítulo entero, el V, pp. 292-333.

37.- All. XVII, 31, p. 85.

38.- Trata de la cuestión también en otra ocasión, cuando aborda el tema de los tributos, y afirma que "Rex [...] postquam semel assumptus, cum populus ei et in eum omnem vim et porestatem trastulisset, libere regimine uti, et quando iuste vectigalia exigere poterit, imponere valebit", all. LIX, 3, p. 299 (en éste caso Larrea está comparando emperador y rey: mientras que el rey tiene el poder, como se puede leer en la cita, para crear nuevos impuestos, el emperador tiene que conformarse con lo que le han concedido "... quia Imperator eligitur et nulla alia quam praedecessoribus data electione conceduntur", ibidem).

39.- Las palabras de F. Tomás y Valiente son aplicables entonces a Larrea, aunque él nunca haya llegado a exponer de forma tan explícita su pensamiento: "ser soberano es hacer valer la propia voluntad, la del Principe, sobre cualquier otra, sobre cualquier otro poder, sobre las mismas normas. Soberanía es la capacidad de hacerse obedecer por todos los súbditos incondicionalmente. El poder de ese Príncipe soberano es absoluto, absuelto, desligado, porque está libre de sumisión a las normas juridicas positivas", en La Monarquía española..., cit., p. 36.

40.- Me refiero sólo al valimiento del conde duque de Olivares: aunque al hablar de la dedicatoria recordé el acceso al poder de Luis de Haro, para el análisis de las cuestiones que ahora se van a tratar no tiene interés, ya que la acción de Larrea que aparece en las Allegationes Fiscales se desarrolló por completo durante el valimiento del Conde Duque.

41.- Sobre el complicado asunto del intento de Olivares de crear una alianza de defensa, en la que las diferentes coronas que constituian la monarquia de España contribuyesen con dinero y hombres a la creación de los ejércitos, llevado adelante sobre todo a lo largo de la década de 1620 , cf. J. H. Elliott, $E l$ Conde-Duque..., cit., pp. 251-283. Para una sintesis del proyecto inicial, cf. J. I. Gutiérrez Nieto, El Sistema fiscal de la monarquía de Felipe $I V$, en J. M. Jovier Zamora (dir.), Historia de España, vol. $\mathrm{XXV}$, cit., pp. 257-331, pp. 310-312. Sobre las ideas políticas de Olivares acerca de la organización de la monarquia de España, cf. F. Tomás y Valiente, La Monarquía española..., cit., sobre todo las pp. 43-63. 
42.- En 1628 el Consejo de Hacienda emprendió una política de recuperación de las Alcabalas de permisión o de tolerancia, cf. S. de Moxó, Los orígenes de la percepción de alcabalas por particulares, en Hispania, LXXII (1952), t. XV, pp. 307-339. Puesto que no había datos sobre la distribución de las alcabalas a particulares, Larrea, en calidad de fiscal del Consejo de Hacienda, "hizo compulsar los libros de Millones", eso es, utilizó los registros de los que pagaban el impuesto de Millones como base oficial para averiguar quien detenía Ias alcabalas. Cf. A. Domínguez Ortiz, Política y Hacienda de Felipe $I V$, Madrid. 1960, la cita se encuentra en Ia p. 190, n. 11 (la relación a la que se refiere, del 1637, se encuentra en el Archivo Histórico Nacional, Madrid, Consejos, leg. 7155). Después del decreto de recuperación de las alcabalas, se puede leer, p. 191: "Un poderoso auxiliar encontró la política regia de recuperación en el fiscal Juan Bautista Larrea". Sobre la alcabala, el principal impuesto ordinario de la época, de tipo indirecto, que gravaba sobre las transacciones comerciales, of. además del texto que se acaba de citar de A. Domínguez Ortiz, y del texto cit. en n. 10, la voz "Alcabala" de M. F. Ladero Quesada en M. Artola (dir.), Enciclopedia de Historia..., cit., vol. V. 1991, pp. 23-24.

43.- El reinado de Felipe IV se abre con la publicación de los Capitulos de Reformacción, a cargo de la Junta de Reformacción, nombrada por Felipe III en la última época de su reinado, con el fin y la esperanza de proponer una reforma realizable. Cf. A González Palencia, La Junta de Reformacción. 16181625. Valladolid, 1932. El autor publica los Capitulos de Reformacción, del 1619, pp. 415-455, y muchos otros documentos de dicha Junta, producidos sobre todo entre 1618 y 1625, (hay uno de 1627). En aquellos años hubo el momento más interesante de la literatura arbitrista, compuesta por quienes, conscientes de la decadencia del momento, proponían arbitrios, eso es, soluciones, y presentaban propuestas más o menos originales y más o menos fundadas, para la recuperación de la monarquía. Sobre el arbitrismo dos textos de referencia son lo siguientes: J. I. Gutiérrez Nieto, El pensamiento económico politico y social de los Arbitristas, en J. M. Jover Zamora (dir.), Historia de España..., cit., vol. XXVI, 19882, pp. 233-351, y J. Vilar Berrogain, Literatura y economia. La figura satirica del arbitrismo en el siglo de oro, Madrid, 1973.

44.- All. LIX, 25, p. 302.

45.- Cf. J. H. Elliott, El Conde-Duque..., cit., p. 575: "la política del conde-duque se veía justificada [...] por la doctrina de la necesidad, que podía resultar de lo más flexible siempre que conviniera".

46.- Es preciso añadir (puesto que en la cita no se dice) que Larrea se está refiriendo al caso del asedio de La Rochelle, en el que España se habia finalmente decidido a apoyar a la monarquía francesa en la lucha contra los Hugonotes. Es posible entonces contextualizar los dos impulsos opuestos que mueven ai autor: por un lado quiere establecer unos límites en los objetivos que España tiene que perseguir; por el otro admite la posibilidad en la que los objetivos sean los correctos, y en este caso quiere abastecer a la monarquía de un fuerte sistema de poder. De hecho, la hipótesis inicial sobre La Rochelle supone que se trate de necesidad urgente; en cambio, a lo largo de la exposición demuestra lo contrario, y entonces no incluye el caso en la categoria de necesidad urgente. Larrea de esta manera ha logrado un doble objetivo: mantener firme el principio que permite los casos de necesidad urgente, y al mismo tiempo, excluyendo un caso concreto, limitar su importancia. De nuevo, es fundamental para la redacción de la alegación el contexto en el que el autor escribe: Larrea no puede olvidar que los recursos de la monarquía están limitados, y que a la hora de proyectar una política de fuerza no se puede prescindir de los medios que hay realmente.

47.- Se trata del comienzo de la dedicatoria que introduce la segunda parte de las Allegationes Fiscales. El fragmento luego alaba los origenes vascos del destinatario de la dedicatoria: "Quid de generis tui splendore referam, et Regia stirpe quae a Biscaiae Regulis Gentilitiis de Haro, Marchionatus del Carpio, dignitatem exhibet, cui hodie Magnatum Castellae excellentia copulata, quae antea maxima, aut maior inter Proceres Hispanos fuit, ab illustri illo Heroë D. Didaco de Haro, Domino Biscaiae, cui Maximos Triumphos adversus Mauros, pro Religione Catholica Reges nostri debuerunt." Si bien para el análisîs deí 
texto he usado un ejemplar de la edición de 1665-66, las citas extraidas de las dedicatorias están cogidas de la editio princeps, 1642-1645 (ejemplar de la Biblioteca Nacional, Madrid, signatura 2/49341), ya que me parecia importante la comparación de la dedicatoria de ediciones posteriores con la de la editio princeps.

48.- La conclusión de la dedicatoria, que aspira a recoger el contenido en pocas frases, ofrece una clara idea de las caracteristicas fundamentales de la relación entre quien redacta y quien recibe la dedicatoria: "Cum igitur in studiis tecum in Collegio Alumnus, et qui originem Biscaiae refero tibi ex Dominis Biscaiae Proceri ii nostri labores (si qui fuerint) merito dicandi, ut magis exhibeam debitum, quam ambitum tanti Patroni. Respice igitur, non despice, Domine, levidense munus, et benignitaie, qua semper me excepisti, favere non desinas. Vale, et vive. Matriti pridie Kalendis Aprilis 1644".

49.- Para la admisión en el Colegio se requerian algunas "pruebas", eso es, la demostración de ser el candidato "cristiano viejo sin tener antepasados judios, musulmanes o penitenciados por la İnquisición", voz "Limpieza de sangre" de M. Rivero Rodriguez, en M. Artola (dir.), Enciclopedia de Historia ..., vol. V, cit., p. 758 .

50.- Hablo de revalorización porque existen señales acerca de la progresiva pérdida de protección y poder por parte de los magistrados. Ya a partir de la época de J. Castillo de Bovadilla, Politica para Corregidores y señores de vassailos, en tiempo de paz y de guerra y para jueces eclesiasticos y seglares, primera edición 1597, (falta la indicación del lugar), copia facsímil de la edición de Anversa, 1704, Madrid, 1978, se habían denunciado los abusos de los señores locales en contra de los jueces, cf., por ej., las siguientes citas: "...en estos pueblos de vandos, y donde hay vezinos poderosos, es necessario tratarlos muy bien de gorra, y condimiento, y castigarlos quando delinquen, sin perdonarles nada: y assi lo he hallado por experiencia porque donde se delinque con el esfuerço del poder, es necessario rigor en la pena...", "tambien deve hazer el Corregidor, que los poderosos restituyan los baldios y concegiles [...] y que en los repartimientos generales de alcavalas y servicios, y otros dacios y tributos, aya igualdad y proporcion", libro III, cap. 9, pt. 12, y lib. II, cap. II, pt. 34.

51.- De la que se hablará más adelante de manera detallada.

52.- All. CI, 23, p. 124.

53.- All. C, 3 y 4, p. 119.

54.- Ibiden, 8, p. 119.

55.-Ibidem, 17, pp. 120-121. Hay que añadir que en este párrafo Larrea atirma que los magistrados són ciudadanos particulares para concluir que se arriesgan más que los soberanos; pero más adelante cambiarả su postura, al afirmar que se puede incurrir en el crimen de lesa majestad en contra de los magistrados, ya que en el cumplimiento de su deber constituyen una parte del rey.

56.- Politica para Corregidores..., cit., libro III, cap. 9 , pt. 12, y lib. II, cap. II, pt. 34; más adelante vuelve sobre el concepto: "...el juez deve administrar justicia, sin embargo de los ruegos de los poderosos...", lib. III, cap. 10, pt 4. En el libro Il ya había denunciado la cuestión, al hablar de los deberes del Corregidor: "a la fortaleza del Corregidor pertenece estorvar [...] que los poderosos y ricos no injurien ni atropellen, ni calumnien, ni usurpen las haciendas a los humildes ni a los pobres...", cap. II, pt. 32.

57.- All. CXVII, 32, p. 201.

58.- All. CI, 27, pp. 124-125.

59.- V. supra, n. 20. 
61. - Su postura cambia según expone los diferentes temas. Acerca de las ventas de los bienes de la Monarquía, por ejemplo, critica algunas cuestiones y llega a proponer aiternativas.

62.- Sobre el tema algunos ensayos de referencia son los siguientes: F. Tomás y Valiente, Ventas de oficios públicos en Castilla durante los siglos XVIl y XVIII, en Gobierno e instituciones en la España del Antiguo Régimen, Madrid, 1982, pp. 151-177 y A. Dominguez Ortiz, La venta de cargos y oficios públicos en Castilla y sus consecuencias económicas y sociales, y Ventas y exenciones de lugares durante el reinado de Felipe $\mathrm{V}$, en Instituciones y sociedad en la España de los Austrias, Barcelona, 1985, a las pp. 146-183 y 55-96 respectivamente.

63.- En Castilla los oficios se empiezan a definir como regalías cuando la monarquía quiere apoderarse de ellos, en el marco de su política regalista a partir de finales del s. XVII, cf. F. Tomás y Valiente, Ventas..., cit., p. 176.

64.- Cf. F. Tomás y Valiente, Ventas..., cit., y A. Domínguez Ortiz, La venta de cargos..., cit., pp. 146183: sobre la participación de la nobleza titulada en la compra de los oficios, Tomás y Valiente no comparte del todo las afirmaciones de Domínguez Ortiz, quien afirma que "todas las clases de la sociedad española participaron en las compras; para las grandes familias fue motivo de lustre y provecho tener incorporados en sus mayorazgos cargos eminentes, regidurias de ciudades de voto en Cortes...", p. 179. Tomás y Valiente considera que la nobleza no tenía fácil acceso a dinero al contado para comprar los oficios.

65.- Se trata, respectivamente, de la ley de 1480 de los Reyes Católicos, que se quería oponer a la privatización de los oficios que se estaba lievando adelante, y de la ley de 1523 del emperador Carlos V, provocada por las preocupaciones expresadas en la sesión de Cortes de Valladolid sobre la difusión de la venta de oficios públicos. Ambas se incluyeron en la Recopilación.

66.- Cf. F. Tomás y Valiente, Ventas..., cit., p. 166: "tales cautelas se abandonan en documentos menos solemnes o más indirectos".

67.- Es la subdivisión propuesta en Ventas..., cit., p. 158, que me parece útil para alcanzar una idea de conjunto del fenómeno. El autor excluye deliberadamente las ventas de oficios de nivel alto, puesto que no se pueden colocar fácilmente en un discurso amplio.

68.- Ya J. Castilio de Bovadilla, Politica para Corregidores..., cit., que escribe, hay que recordario, en 1597, se muestra interesado por el problema, cf. lib. I, cap. III, pt. $2 \mathrm{l}$ : "que venderse los Oficios y magistrados, no es otra cosa, sino colocar en los tribunales la avaricia, y no la justicia: y vender juntamente la justicia, vender la Republica, vender la sangre de los subditos, vender las leyes...".

69. - Cf. F. Tomás y Valiente, Ventas.., cit., p. 169: "esta operación de acrecentamiento de oficios, y en particular la de acrecentamiento de regidores, fue posiblemente la de más importantes consecuencias".

70.- Esto se hace evidente a través de las afirmaciones de Larrea. Cf. además A. Dominguez Ortiz, La venta de cargos..., cit., p. 152: "la facultad de disponer del cargo por vía de arrendamiento o venta (pues, en el fondo, las renuncias o traspasos equivalian a esto)...".

71.- Con las premisas antes expuestas, uso sin distinción los términos renuncia y venta, para referirme a la venta. En este sentido, también el adjetivo "renunciable" y el substantivo "renunciabilidad" se usan en el sentido de ausencia de prohibición de la renuncia. Uso dichos términos con este significado traduciéndolos literalmente del latín de Larrea. 
73.- La lista se puede leer en A. Dominguez Ortiz, La venta de cargos..., cit., p. 150, n. 10.

74.- All. XCIV, 22, p. 98

75.- O sea, la segunda de las leyes arriba citadas, publicada por Carlos V en 1523, v. supra, n. 65.

76.- All. XCIV, 2, p. 96.

77.- J. H. Elliott, El Conde-Duque..., cit., p. 415, tras haber dibujado en las páginas precedentes la preocupante situación económica de finales de los años veinte y principios de los treinta del s. XVII, describe los expedientes encontrados en 1630, con el asentimiento de una junta de teólogos, para salvar la hacienda estatal: "los medios de hacer dinero aprobados por los teólogos incluían la idea [...] de la venta del cargo de alguacil mayor en los pueblos de más de quinientos habitantes, así como la de otros cargos locales y la creación de otros nuevos".

78.- Cf. la descripción de las distintas profesiones, en J. Castillo de Bovadilia, Politica para Corregidores..., cit.: en el lib. I, cap. XIII, afirma que el alguacil tiene tareas de "executor de la justicia".

79.- All. CVIII, se trata del resumen inicial, p. 146.

80.- Ibidem, quaestio, p. 147.

81.- Ibídem, 3, p. 147. Vuelve sobre el concepto en los puntos 5,18 y 20.

82.- De la Junta de Reformacción, de los Capitulos y de la bibliografia de referencia ya se ha dicho, v. supra, n. 43.

83.- All. XL, 1, p. 200.

84.- F. Tomás y Valiente, Ventas..., cit., pp. 167-168, indica entre los "principales procedimientos elegidos [...] para beneficiarse económicamente con el tráfico de oficios públicos" el de "operaciones colectivas de ventas de oficios concertadas por «asiento» con un importante agente o factor. Este sistema tenía la ventaja de que o bien el factor adelantaba a Hacienda el importe global de la operación, y él se resarcía de ella vendiendo uno tras otro los oficios indicados en el contrato («asiento») con la Corona; o bien (hecho mucho más frecuente) la Hacienda real saldaba sus deudas previas con dicho factor, autorizándole a vender oficios cuyo importe total se calculaba equivalente a la deuda a favor de tal acreedor". Creo que el caso aqui tratado no se corresponde del todo con ninguna de las hipótesis referidas, pero no es muy diferente.

85.- All. XL, 5, p. 200.

86.- Es la quaestio de la ail. CXIX, p. 216.

87.- Sobre la licitud de la venta de los oficios, cf., por ej., ibidem, al punto 3, p. 216 : "...quia dominium officiorum in Principe consideratur, et ideo vendere illa poterit, quia cum bona temporalia sint, possunt aestimari pretio [...] et ex communi Theologorum sententia officia ex sua natura esse vendibilia, et pretio aestimabilia, cum sint temporalia, honorifica et utilia, et venditio procedat, si non habent aliquid spirituaie annexum". Por otra parte, sobre la prohibición para el príncipe de crear nuevos oficios, incumpliendo los términos del compromiso que había aceptado, cf., por ej., el punto 5, p. 216: "Sed contraria sententia, ut quando Princeps in venditis officiis se obligaverit alia nova non vendere, vel creare, aut si ex venditione novi officii, aliorum, quae iam vendita, exercitium impediatur, vel emolumenta diminuantur, non posse Principem id facere, et ius acquisitum tollere, pluribus rationibus, et authoritatibus comprobatur. Nec 
agimus de potestate Principis, sed de voluntate, ut alias diximus I p. decis. Granat. 8 n. I, quia semper creditur Principem iustum quod fuerit, decernere velle".

88.- Ibidem, 23, p. 220. Considero necesario subrayar que aquí Larrea está expresando su opinión personal, bastante separada de la postura profesional que se observa en otras alegaciones. Para corroborar ésto puede ser útil la lectura de la siguiente cita, extraida de una alegación sobre otro tema. Se trata de la facultad para el rey de no incluir el aumento del impuesto sobre el transporte del correo, concedido por las Cortes, en el "asiento" estipulado anteriormente para el cobro de dicho impuesto. Afirma: "quia si praeiudicium Cursoris Maioris [que había cogido el "asiento"] esset in consideratione, ut impediretur collectam et tributum imponi, similiter dicendum esset venditis, vel concessis officiis a Principe in aliquo loco non posse alia officia instituere, eo quod fieret praeiudicium electis in officiis, si alii plures extarent, qui idem munus obtinerent, quia utilitas muneris, et auctoritas minueretur, si cum pluribus aliis commoda officiorum communicarentur, quod in muneribus Decurionum, officiis Tabellionum, et aliis similibus, sine dubio contra obtentum fuit, ut possit Princeps ad libitum, si aliquid contra non conventum, officia minuere vel augere, et pertinet ad eius Regalia, quibus infixum est, et annexum eius supremae potestati", all. LVI, 10, p. 290.

89.- Al final de la all. escribe que "talis venditio pestis Reipublicae censenda", all. CXIX, 23, p. 220.

90.- En la portada de la segunda parte de las Allegationes Fiscales se puede leer esta interesante anotación: "Allegationum / Fiscalium / Pars secunda / In qua, ultra iuridica, plura politica elucidantur".

91.- All. CXIX, 23, p. 220.

92.- Ibidem, 24, p. 220.

93.- V. supra, n. 23.

94.- Existen algunas alegaciones en las que Larrea se opone a las decisiones del rey: por ejemplo, la que trata de la intervención al lado de los franceses a La Rochelle, que ya se ha mencionado (n. 46). Pero cuando digo que Larrea no se opone a la acción del rey, me refiero a sus decisiones cotidianas acerca de las relaciones con los diferentes interlocutores que la monarquía tenía. El caso de La Rochelle, en cambio, es diferente, ya que se trata de política internacional.

95.- V. supra, n. 90.

96.- Se entendía con esto la venta de lugares de realengo, con cierta jurisdicción. Cf. A. Dominguez Ortiz, Ventas y exenciones de lugares durante el reinado de Felipe $I V$, en Ynstituciones y sociedad..., cit., pp. 55-96. Transcribo como ejemplo algunas cláusulas de la venta de 20.000 vasallos llevada a cabo en 1626: la venta incluía "la jurisdicción civil y criminal, alta y baja, mero y mixto imperio; los señores podían poner alcaldes mayores que juzgasen las causas en primera instancia (la segunda se vendía aparte)...", p. 60. Más adelante, se habla de la venta de 1638, y se dice: "los detalles de la operación [fueron] semejantes a los de las anteriores", p. 61.

97.- Ibidem, p. 75. Anteriormente, p. 73, se había detenido en el tema: "es indudable que la frase vender vasallos tiene más de escandalosa en las palabras que en la realidad [...] ¿qué es lo que el comprador adquiria? [...] En las cédulas de factoria se expresa que los lugares se venderian «con jurisdicción civil y criminal, alta, baja, mero mixto imperio, señorío y vasallaje, penas de Cámara y de sangre, calumnias, mostrencos y demás rentas jurisdiccionales, con las escribanias si fuesen anexas a dicha jurisdicción». Lo que se ocultaba bajo esta pomposa palabreria era poca cosa; el derecho a poner justicias en las localidades pequentas resultaba más gravoso que útill".

98.- Ibidem, p. 69: "aigunas villas que habian comprado su jurisdicción, abrumadas por ell peso de los 
censos que tuvieron que contraer, acabaron por declararse vencidas".

99. - Ibidem, p. 62 y p. 68 .

100.- All. XLV, 20, pp. 225-226.

101.- Parece que en este caso concretamente con Tanteo se denomine al derecho del lugar de comprar la jurisdicción por el mismo precio ofrecido por un particular, y no también por un precio menor, con la única cláusula de subir un dos por ciento el precio inicial.

102.- All. XLV, 12, p. 224. 